\title{
Multidisciplinary Exploration of DRAGON: an ONERA Hybrid Electric Distributed Propulsion Concept
}

\author{
P. Schmollgruber, C. Döll, J. Hermetz, R. Liaboeuf, M. Ridel, \\ ONERA, the French Aerospace Lab \\ F-31055 Toulouse, France \\ I. Cafarelli \\ ONERA, the French Aerospace Lab \\ F-92322 Châtillon, France \\ O. Atinault, C. François \\ ONERA, the French Aerospace Lab \\ F-92190 Meudon, France \\ B. Paluch \\ ONERA, the French Aerospace Lab \\ F-59045 Lille, France
}

For civil transport aircraft, decreasing the Fan Pressure Ratio has been a solution to improve fuel efficiency. There is however a limit associated to this approach because of the resulting size of the fan. One solution to the problem is Hybrid Electric Distributed Propulsion as electric motors do not loose efficiency when scaled down and the large number of fans allows to maintain a low Fan Pressure Ratio without geometry issues. Within the European Programme Clean Sky 2, ONERA decided to explore the possible implementation of Hybrid Electric Distributed Propulsion on a transport aircraft carrying 150 passengers at a cruise Mach number of 0.78 over a range of $1200 \mathrm{NM}$ to match airlines flexibility requirements. To perform conceptual design studies, a research baseline concept called DRAGON (Distributed fans Research Aircraft with electric Generators by ONERA) has been defined. Characterized by distributed fans located all along the wing span on the pressure side in a rearward position, this configuration has been investigated by disciplinary experts. Concurrently, fuel consumption benefits have been computed for various technology options.

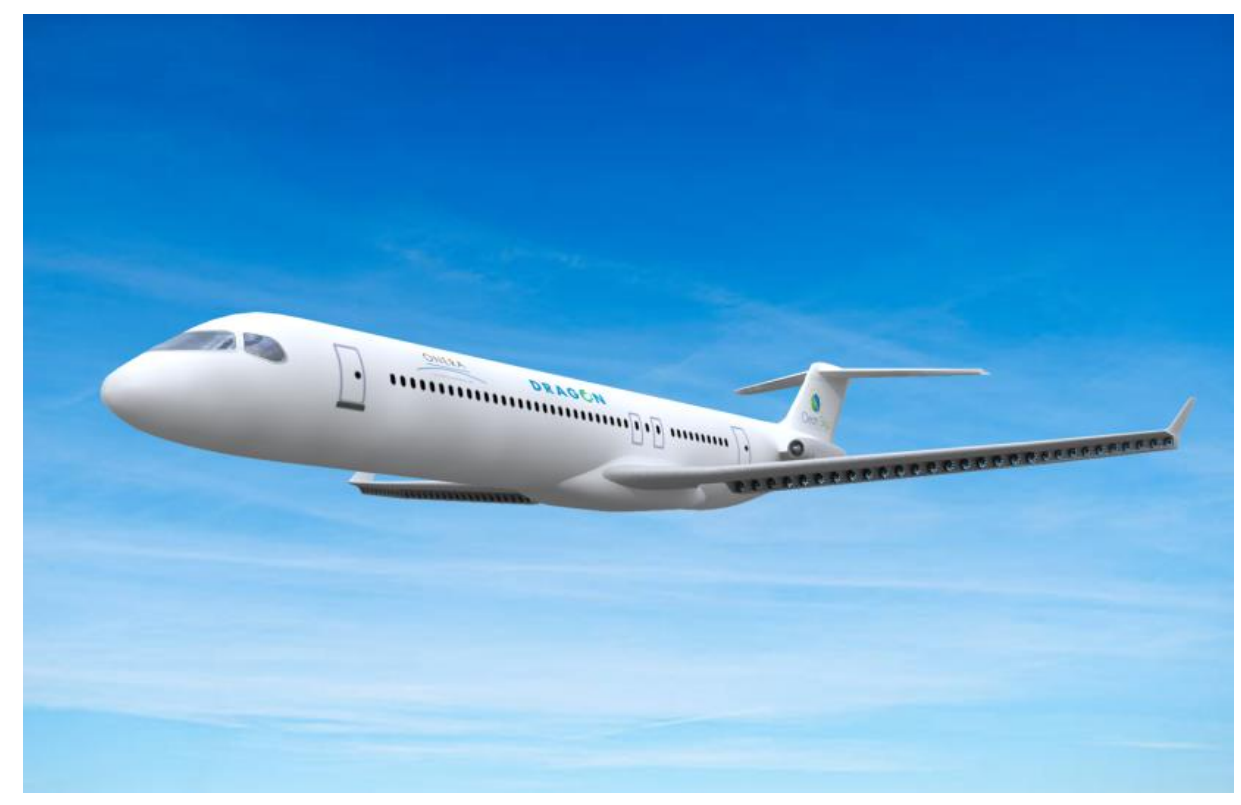

Figure 1: Illustration of the DRAGON concept 


\section{Nomenclature}

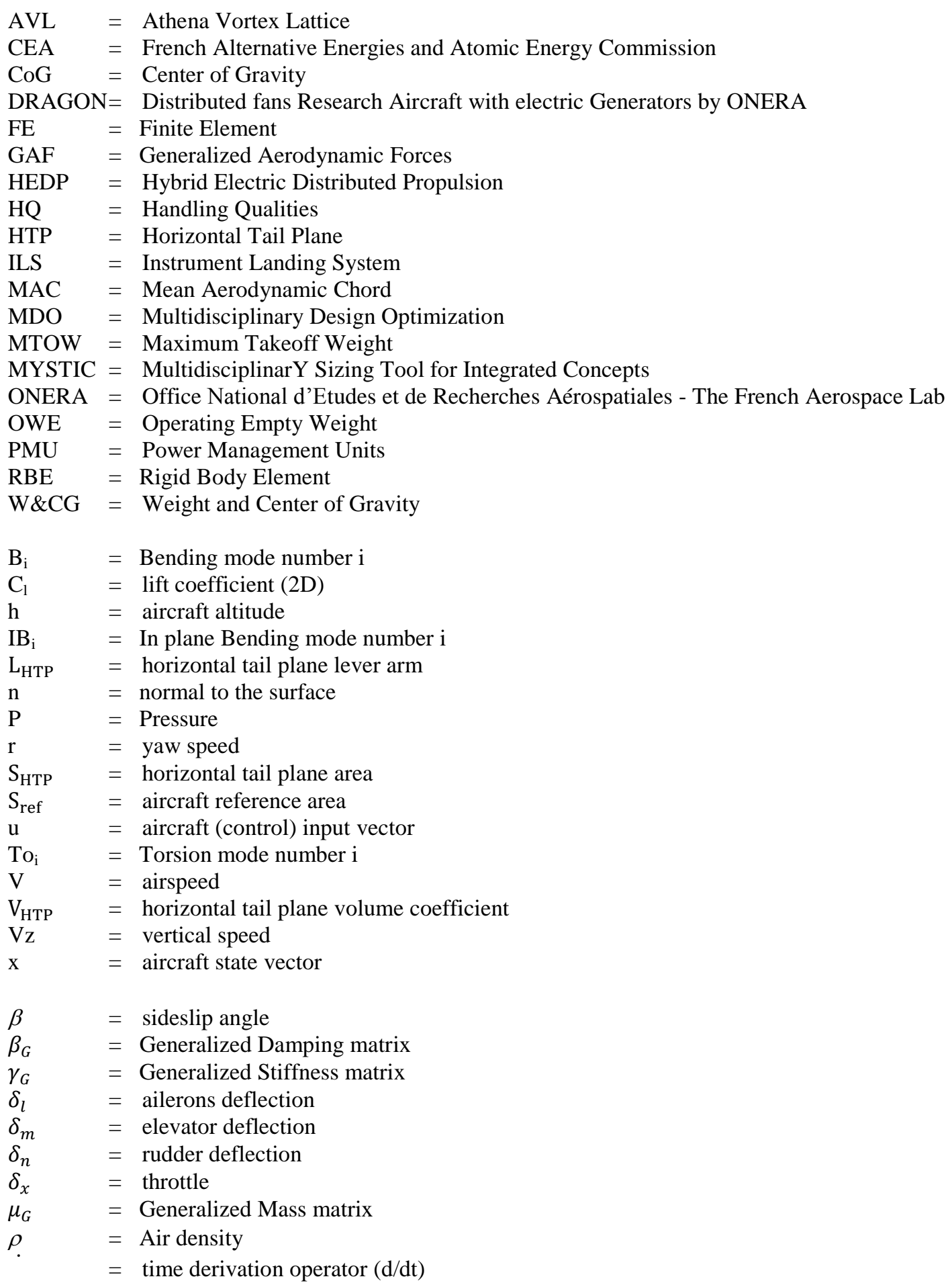




\section{Introduction}

In order to outlast competitors or to meet stringer environmental constraints, aircraft designers have always explored potential benefits associated to unconventional configurations ${ }^{1}$. Regarding civil transport, studies that took place in the last decade identified promising solutions such as Blended Wing Body ${ }^{2}$ and Strut Braced Wing. More recently, the progress made in the field of electric components and the associated technologies has offered new degrees of freedom when defining the next generations of airplanes ${ }^{4}$. At ONERA (The French Aerospace Lab), internal studies in collaboration with CEA (French Alternative Energies and Atomic Energy Commission) carried out in 2011-2012 led to a preliminary survey of hybrid electric aircraft for different missions. One of the conclusions of this research was the importance of the distributed propulsion technology in order to obtain efficient flight vehicles ${ }^{5}$. Not only it can offer positive aero-propulsive benefits, it is also applicable to various classes of vehicles ${ }^{6,7}$. In order to enable the maturation of Hybrid Electric Distributed Propulsion (HEDP), ONERA started in 2013 the project AMPERE focused on applying DEP (distributed electric propulsion) on a general aviation aircraft concept ${ }^{8}$. To better understand the physics associated to a large number of ducted fans over a wing, numerical simulations were carried out and a wind tunnel test campaign (2017) provided valuable data for validation. In parallel, ONERA collaborated with ISAESUPAERO to explore the design space of a Large Passenger Aircraft using distributed propulsion ${ }^{9}$.

To complete its understanding of such aero-propulsive layout, ONERA decided in 2018 within the European Programme Clean Sky 2 to investigate distributed propulsion for high speed applications as reference missions of the single aisle segment (A320 or B737) feature cruise segments at a speed of about Mach 0.8. Early discussions at conceptual design phase highlighted the necessity to gather accurate information at disciplinary level. Thus, ONERA defined a baseline research concept to be shared among the various disciplinary experts. In the first part of this paper, the main elements associated to the selected high-speed distributed propulsion architecture are presented. Second, the overall layout of the research concept identified as DRAGON (Distributed fans Research Aircraft with electric Generators by ONERA) is explained. Subsequently, all concurrent studies performed on DRAGON are presented including overall design loops made with the sizing tool MYSTIC (MultidisciplinarY Sizing Tool for Integrated Concepts) ${ }^{10}$.

\section{Definition of the high-speed distributed propulsion architecture}

\section{A. Rationale of Distributed Propulsion for Large Passenger Aircraft}

In the last decades, major reductions in fuel consumption have been directly related to aerodynamics improvements, use of new materials and the introduction of new turbofan technology. For this latest category, Sforza indicates that Specific Fuel Consumption is strongly reduced by an increase of the bypass ratio ${ }^{11}$. Associated to a decrease of the Fan Pressure Ratio, this idea of continuously increasing the size of the fan for future aircraft is however jeopardized because of geometrical constraints as illustrated in Figure 2.

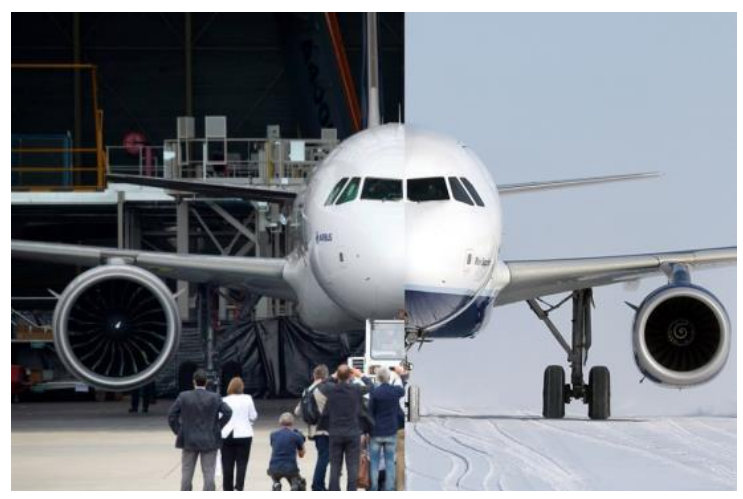

Figure 2: Illustration of the limited margins for further increase of fan diameter on Small-Medium Range airplanes $^{12}$

It is known that by multiplying the number of fans for a given thrust, there is the possibility to both maintain a low Fan Pressure Ratio and limit geometry issues. Until now, such solution couldn't be applied as the fans were associated to engine cores that were less effective when scaled down. Today, if these fans are connected to electric motors, this limitation on efficiency disappears as there are no negative scale effects ${ }^{13}$. Thus, Hybrid Electric Distributed Propulsion becomes an enabler for increasing the aircraft propulsive efficiency. 


\section{B. Position of the ducted fans}

When investigating Hybrid Electric Distributed Propulsion (HEDP), the work reported by Wick ${ }^{14}$ is a valuable reference as it provides a large design space exploration for the fan position on the airfoil. After a detailed review of the results, one promising option for high speed cruise Mach number features the engine on the pressure-side of the airfoil (Figure 3). Indeed, the key issue at high speeds is that the upper wing in transonic condition contains a supersonic area which is very sensitive to any obstacle (an upper engine configuration could trigger buffet onset for example). Therefore the suction side must remain as clean as possible. Furthermore, the pressure side naturally helps to slow down the flow upstream of the engine inlet. Consequently, the pressure side-rearward position has been selected by the DRAGON team as the starting point of the design.

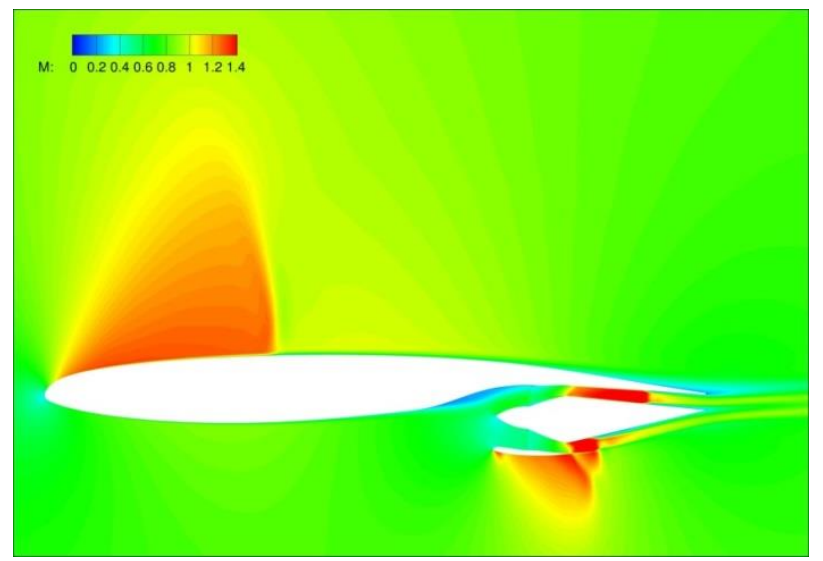

Figure 3: ONERA CFD computation performed on a high speed embedded distributed configuration

\section{Hybrid Electric Distributed Architecture}

As distributed propulsion and overall aircraft efficiencies are strongly affected by the electrical architecture, ONERA studied various options for the complete electric chain. Given their level of performance and their zeroemission capabilities, hydrogen and fuel cells would have been good candidates to power DRAGON. However, foreseeing the increase of operational complexity associated to such an energy source, the design team opted for a more conventional solution. The electricity used to run the electric motors and their ducted fans would be produced by generators coupled to turboshaft engines burning regular kerosene.

During the conceptual design phase of this Hybrid Electric Distributed Architecture, it was clear that failure cases would be the main driver. As distributed propulsion has a direct role on aircraft aerodynamics and thus its efficiency, designers selected an architecture minimizing the possibility of inoperative ducted fans. To this end, a redundant architecture illustrated in Figure 4 has been selected. The main idea is to have all sources (turboshaft and generator) connected to the Power Management Units (PMUs) through Alternative Current cabling. Thus, in case of failure of one source, the other one(s) would still be able to provide the required power to all ducted fans. The PMUs are made of a bus and converters in order to dispatch Direct Current to inverters located near each electric motor. Depending on the disciplinary analyses and the overall aircraft assessments, the number of electric motors (fixed to 40 as a starting point) will evolve and their alternate arrangement along the wing span will be optimized so that the failure of a single PMU doesn't affect large areas of the wing. In the illustrated arrangement, there are 4 PMUs (identified from A to D) driving each one 10 electric motors.

Always in Figure 4, the Hybrid Electric Distributed Architecture with 4 sources is shown. The rationale for this choice is empty weight reduction as in the case of a turboshaft failure, it is better to distribute the required power on 3 turboshafts instead of 1 . However, it is also known that the fuel consumption of turbine engines decreases with size. For this criterion, 2 large turboshafts would be more efficient than 4 . As there is still some uncertainty on the disciplinary or systems models used in the overall aircraft performance assessments with MYSTIC in the early phases of the design, engineers preferred to keep the number of turboshafts as an open option. Also, the subsequent configuration exploration could affect this choice. 


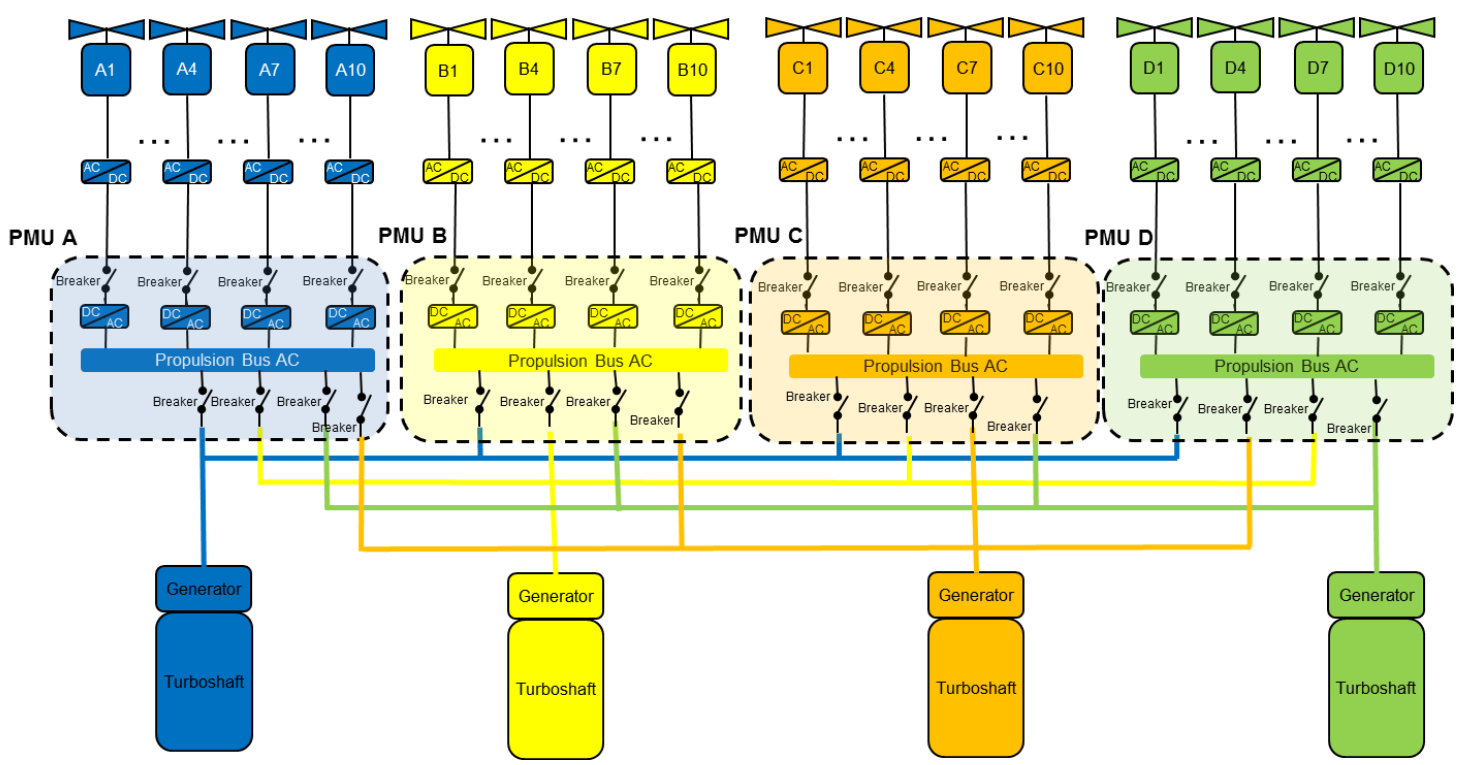

Figure 4: Reference distributed electrical architecture with redundancy on the energy sources (the 4 turboshaft option is shown)

Last but not least, the selected architecture doesn't feature batteries for the propulsion chain. The driver for this decision is the important penalty in terms of weight associated to this type of energy source. Indeed, when considering typical mission for Large Passenger Aircraft with stringent requirements on range, the increase in mass would rapidly cancel any asset brought by the batteries.

\section{Definition of the DRAGON layout}

The definition of the DRAGON layout is solely driven towards the increase of maturity of the high speed distributed propulsion technology. From an aircraft design point of view, this high level objective translates into the development of a configuration that allows unbiased disciplinary investigations and better understanding of aeropropulsive effects. About the reference mission, DRAGON has to carry 150 passengers at a cruise Mach number of 0.78 for a design range that is above $800 \mathrm{NM}$. As the key element in the configuration is Hybrid Electric Distributed Propulsion, the design team anticipated various possibilities regarding the spanwise position of the ducted fans. Following exchanges among experts within the multidisciplinary design team, it has been decided to place ducted fans on the entire available span length. The reasons for this choice are: (i) maximization of the aero-propulsive effect of distributed propulsion, (ii) investigation of the distributed propulsion spanwise effects on lift, (iii) simplified transposition of 2D CFD analyses to the 3D finite wing case of interest.

With the HEDP characteristics set, the DRAGON design started by fixing the cabin arrangement and the associated fuselage considering a conventional cross section. For the overall configuration, given the position of the ducted fans, ONERA looked at different landing gear layouts. The first one corresponds to a classical layout with the main landing gear at the front. The asset associated to this configuration shown in Figure 5 is to prevent any Foreign Object Damage to both the turboshafts located in the belly fairing and the ducted fans. 

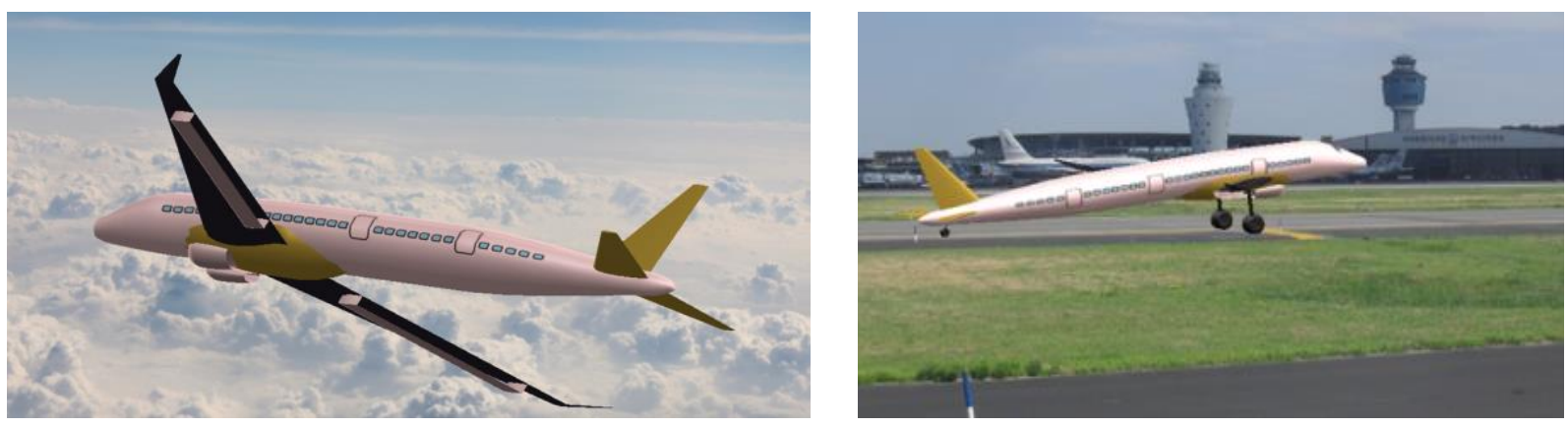

Figure 5: Configuration exploration based on a classical landing gear layout

The second solution illustrated in Figure 6 features a tri-cycle landing gear. With the idea of accommodating 4 turboshafts to maximize the distribution of energy sources, this airframe architecture is based on podded landing gears behind turboshafts like on the Tupolev Tu-95. In this manner, interferences between the landing gear strut and the distributed fans on the lower surface are limited. As shown in Figure 6, different options for the location of the remaining two turboshafts have been considered (at the wing / fuselage junction or at the rear of the fuselage).
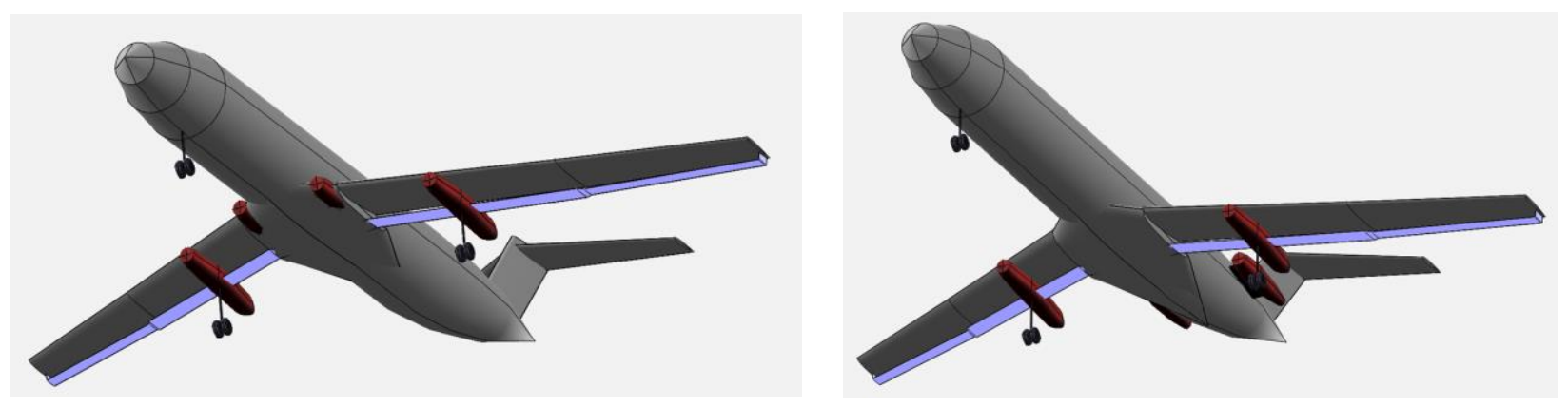

Figure 6: Configuration exploration with podded landing gears at the rear of under the wing turboshafts

After further discussions between disciplinary experts and aircraft designers, it appeared that both options had some inherent risk: the classical landing gear layout is known for limited control at low speed while the podded landing gear could both affect the wing sizing and interact in a complex manner with the distributed fans. These risks could be mitigated with specific studies but as the focus of DRAGON is to mature the distributed propulsion technology, ONERA decided simply to cancel them by selecting a tri-cycle layout with the distributed fans area limited by the position of the main landing gear (Figure 7). With this aspect frozen, designers and handling qualities specialists agreed to select a T-Tail option for the horizontal tail. In this manner, the higher position limits the interactions with the main wing and the fan flow. Following the lessons learned on AMPERE ${ }^{15}$, the team adopts the solution of a movable horizontal tail for trim to get more operational flexibility.

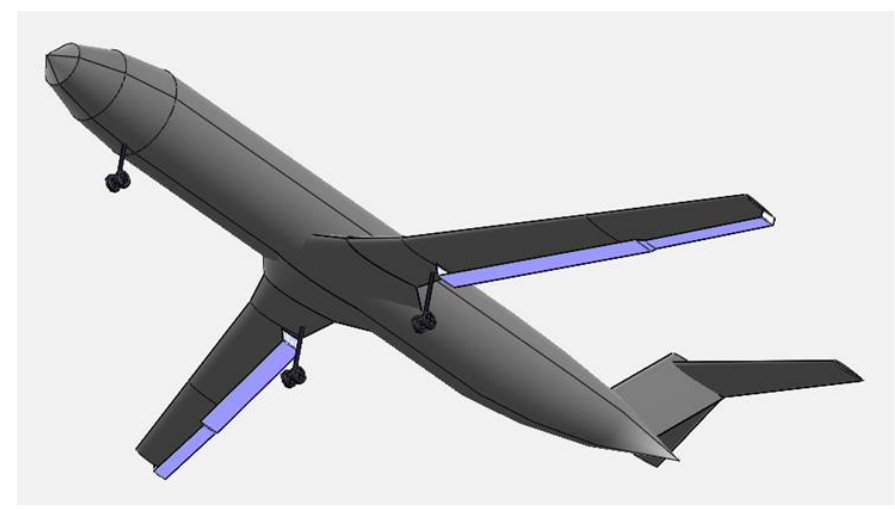

Figure 7: DRAGON landing gear layout and distributed fans location 
For the positioning of the 4 turboshafts, the option implemented on the VC-10 and Il- 62 has been considered. However, Roskam ${ }^{16}$ stressed different issues with such a solution. Thus, different configurations illustrated in Figure 8 have been considered. Unfortunately, the proposed solutions had all critical aspects that needed further investigation: when locating the 4 turboshafts in the rear area, the shifted positioning to take into account rotor burst requires careful evaluations. The other option inspired by the Honda $\mathrm{Jet}^{17}$ proposes to place the engines over the wing. Although promising, this solution would require an important work on both structural design to assess wing weight and aerodynamic analysis to make sure that the high cruise Mach number wouldn't generate degrading conditions.
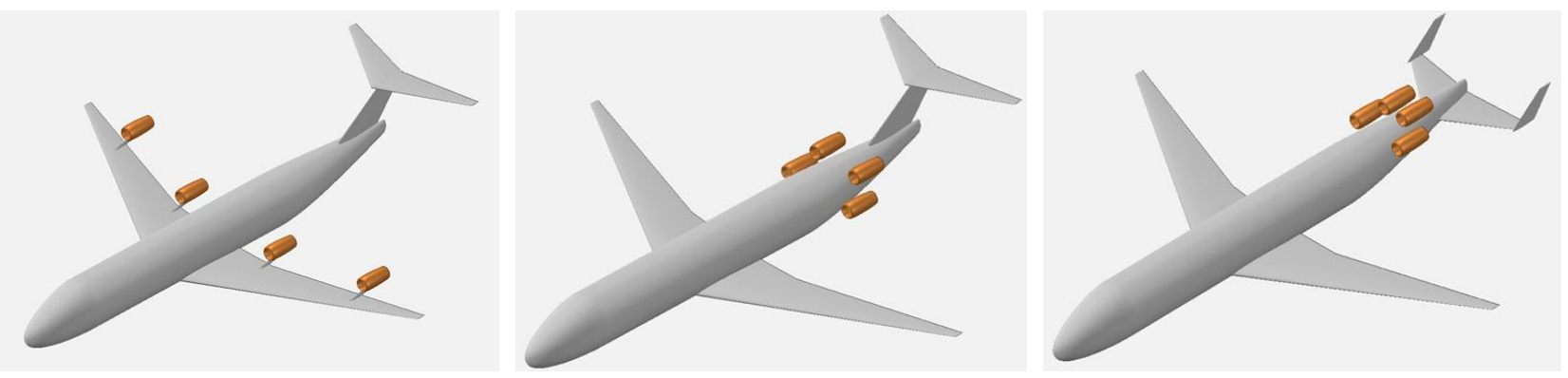

Figure 8: Options to locate four turboshafts

More important, these mandatory studies would shift the technical focus away from the high speed distributed propulsion technology that is the primary goal of the research. Therefore, in the frame of the project, the design team opted for a simpler distributed electrical architecture with only two turboshafts at the rear (Figure 9). Nevertheless, subsequent disciplinary studies focusing on the electrical architecture still consider the option with four energy sources, especially to evaluate benefits in case of failure.

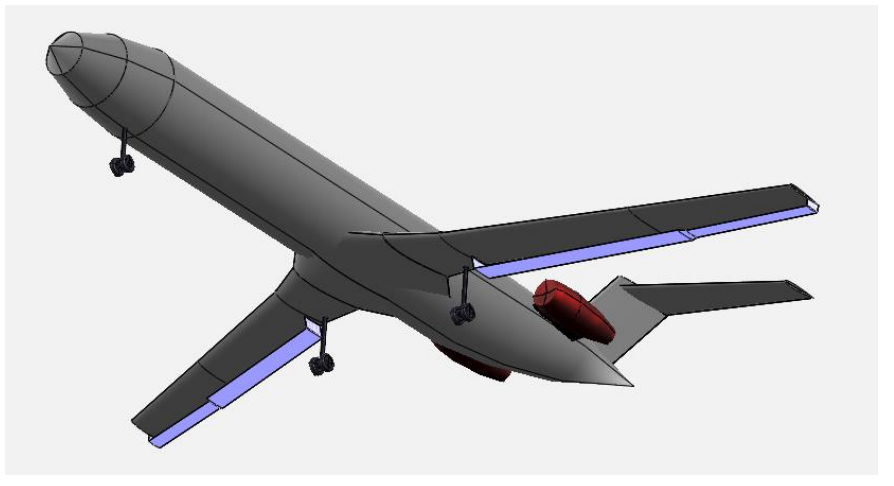

Figure 9: The selected configuration for DRAGON

With the configuration layout fixed, the design team carried out the preliminary arrangement of the electric chain components identified in Figure 4, this time considering the 2 turboshaft option. This final layout is shown in Figure 10: as expected, the electric motors and the fans are located at the trailing edge. For the inverters, as they will generate some heat, it is planned to put them in the leading edge area so that they can be used as anti-icing devices. Regarding the energy distribution, PMUs have been positioned in the front cargo bay so that the large number of cables can run through the wing. For the fuel, it can be stored in a Center Tank installed in the rear cargo hold area of the fuselage ${ }^{18}$ (the volume available is compatible with the preliminary fuel consumption estimations - see last section). As a large portion of the cargo volume is taken, it is clear that DRAGON doesn't meet all airlines requirements in terms of operational flexibility. This characteristic highlights the fact that DRAGON shouldn't be considered as a finalized airliner but as a technology demonstrator.

With the general layout of DRAGON frozen, concurrent disciplinary assessments and overall performance estimations have been carried out. For these conceptual design level explorations, different competence levels of disciplinary analyses ${ }^{19}$ have been used to acquire a better overall configuration knowledge including assets and drawbacks identification. 


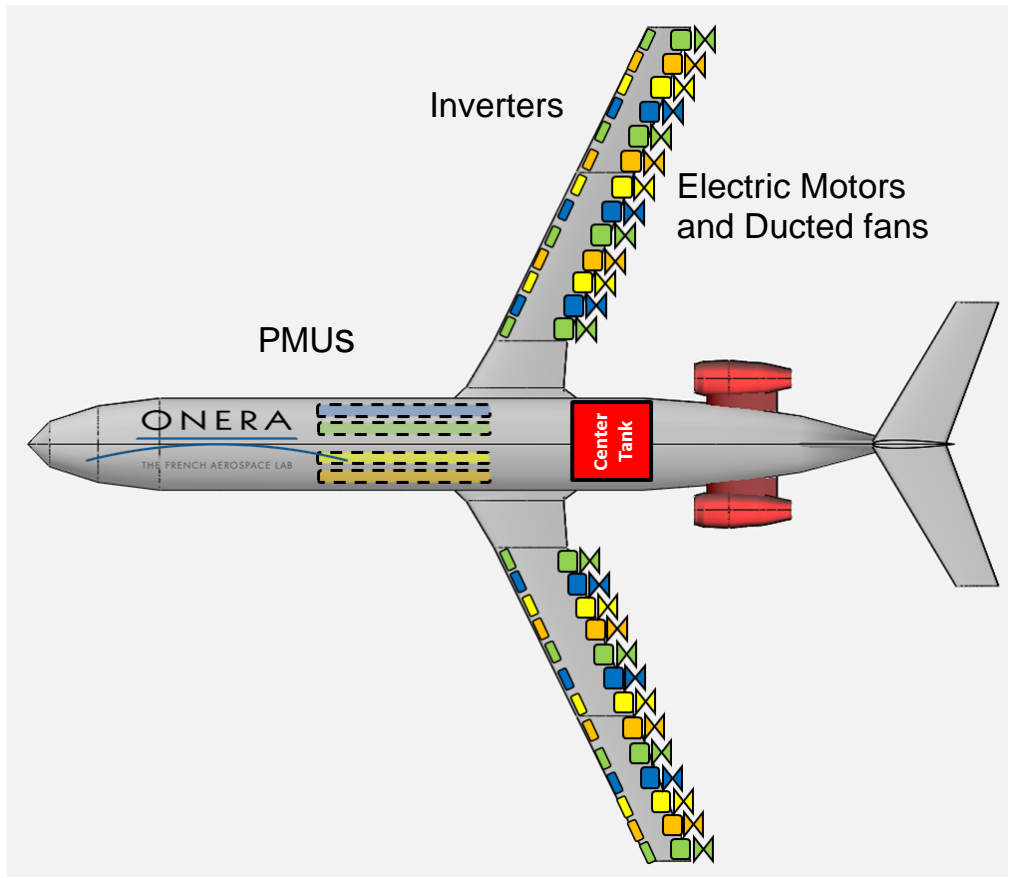

Figure 10: Preliminary layout for DRAGON (fan number to be consolidated)

\section{Concurrent analyses}

\section{A. Aerodynamics}

In AMPERE, wind tunnel tests showed the possible gains in terms of maximum lift coefficient when ducted fans are blowing on the wing upper surface ${ }^{20}$. In a recent work, ONERA and ISAE-SUPAERO found out that such blowing effects can lead to a non-negligible reduction of the wing area. This effect that translates into an empty weight reduction has a positive snowball effect at aircraft level in terms of fuel consumption.

However in transonic flight conditions, the upper wing leading edge engine integration as in AMPERE would be located in the region of supersonic flow, which is very efficient to generate lift (supercritical airfoils). A back-up solution could be to integrate the engine on the upper wing trailing edge, as explored by ONERA in DisPURSAL EU project $^{21}$ (see Figure 11). In that case, the supersonic region on the upper wing is protected, but it is dramatically influenced by the engine thrust level. Therefore the wave drag depends a lot on the thrust setting, and cannot be minimized as well as it is on modern airliners. Moreover, the non-reversible loss of total pressure due to the shock is ingested by the engines, reducing the propulsive efficiency. Last but not least, in case of buffet onset or even stall, the unsteady separated flow would directly be ingested by the distributed fans, reducing thrust and causing fatigue on the fans.

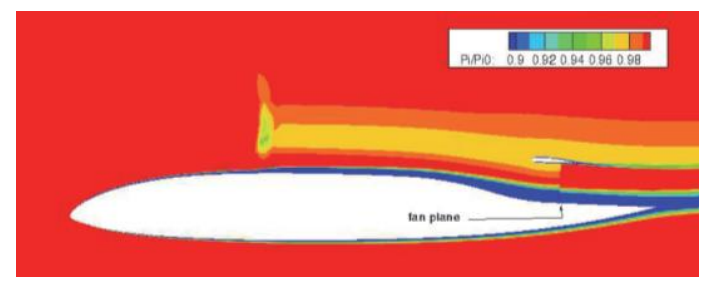

Figure 11: Upper wing engine ingesting total pressure loss from wing shock (EU DisPURSAL ${ }^{21}$ )

Therefore and as previously indicated in the second section, ONERA decided to look at a compromise in terms of engine integration, with a lower wing trailing edge configuration. 

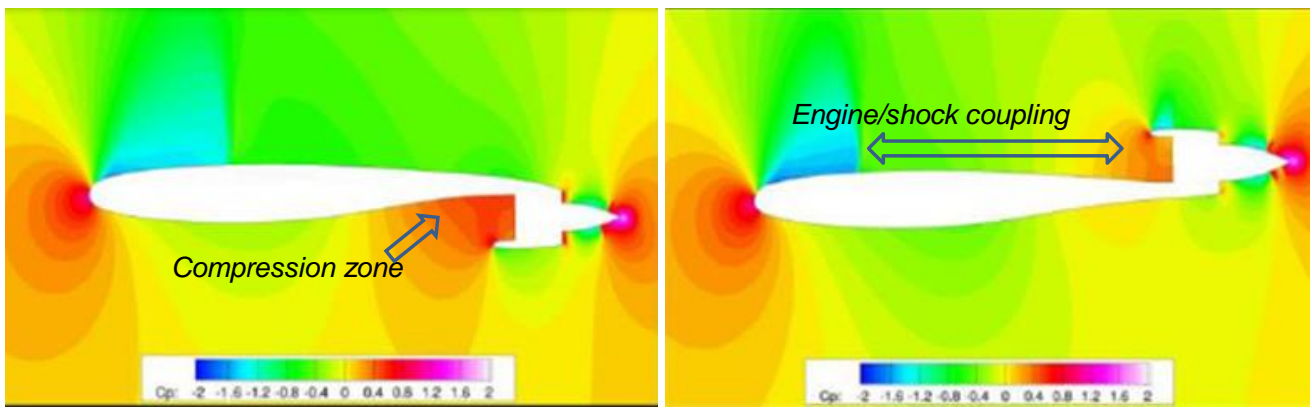

Figure 12: Lower wing trailing edge engine integration versus upper wing ${ }^{14}$

ONERA's choice is theoretically beneficial for the upper wing behavior in transonic conditions. The engine being located on the lower wing, the supercritical characteristics of the airfoil should be preserved, allowing mitigating the upper wing wave drag rise. All the issues concerning buffet onset or stall are also eliminated. Furthermore the intake of the engine would be located in the compression zone of the supercritical airfoil. As it is necessary to slow down the flow before the fan, this location should also be beneficial as shown in Figure 12.

However at low speed, a large increase of maximum lift coefficient wouldn't be possible with the selected layout for DRAGON (Figure 3). This position is indeed not favorable for low-speed conditions, compared to an upper wing propulsive integration. The aerodynamics team at ONERA proposed then the concept of "propulsive flap" as sketched in Figure 13, where part of the fan jet would be used to blow a flap, thus increasing the efficiency of the high-lift system. This solution to be integrated in DRAGON matches then high-speed and low-speed requirements at the price of a higher complexity.
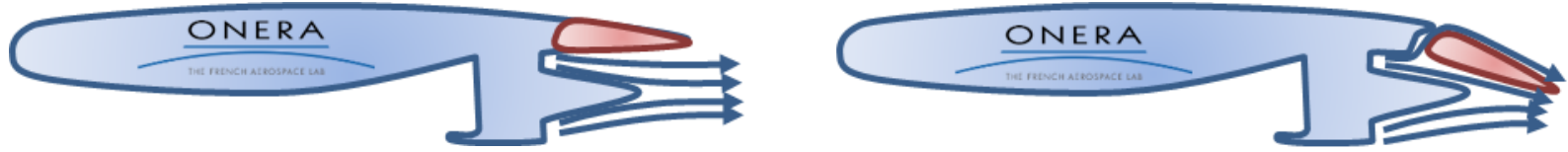

Figure 13: "Propulsive flap" concept at cruise (left) and in high-lift position (right)

But transonic aerodynamic design is always a challenge. Placing the engine on the lower wing as illustrated in Figure 14 creates a divergent nozzle, which accelerates the exhaust flow to large supersonic speeds, easily triggering flow separation in the nozzle ${ }^{14}$.

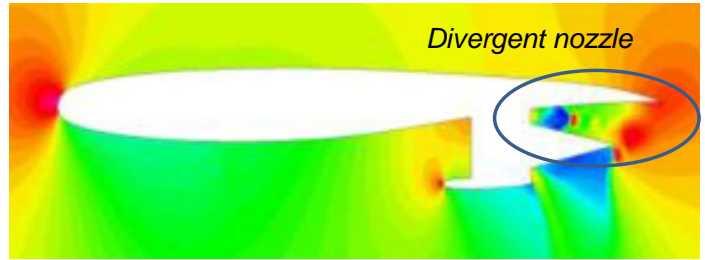

Figure 14: Lower wing trailing edge engine integration with diverging nozzle ${ }^{14}$

This is why ONERA's design activity is currently focused on this part of the design, the low speed design being looked at later. All following pictures come from CFD computations performed at $\mathrm{M}=0.80,35000 \mathrm{ft}$ on a $2 \mathrm{D}$ infinite wing with $25^{\circ}$ of sweep angle. This simplified approach is a basis to quickly explore the design space.

The first computed design is unrealistic but serves as a clean aerodynamic target. The engine is placed at the very end of the trailing edge (so it would not be possible to attach it on the wing), thus giving a smooth flow everywhere, and preventing having a diverging nozzle (Figure 15). A tilt effect (engine axis orientation) was performed, which demonstrated a huge sensibility to the aerodynamic lift coefficient. This is easily explained by the nozzle flow orientation, which directly pilots the wing trailing edge downwash, causing large variations of lift for a fixed angle of attack. Based on these first configurations, the next step consists in placing the engine at a more forward position, while mitigating the divergent nozzle issue. 


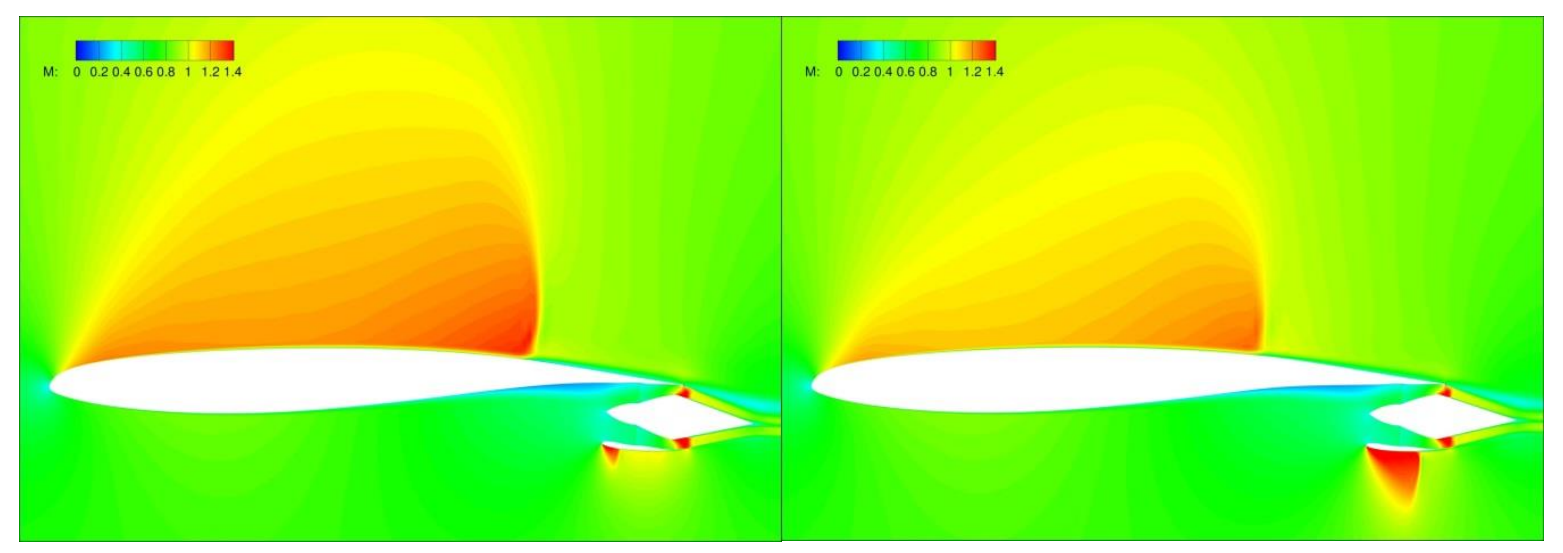

Figure 15: Aerodynamic target - an unrealistic configuration but with a clean flow. On the right, the engine has a lower tilt angle compared to left picture, impacting the airfoil lift coefficient (weaker upper wing shock, larger engine nacelle shock). Both computations are at $\mathrm{M}=0.80,35000 \mathrm{ft}, \mathrm{AoA}=0^{\circ}$

After some design iterations (in order to remove several flow separations), a first acceptable design was produced as illustrated in Figure 16. The engine is semi-buried close to where may lie a rear spar. First, it must be noted that a larger angle of attack is required to reach $\mathrm{Cl}=0.5$ ( $3^{\circ}$ instead in Figure 16 instead of $0^{\circ}$ in Figure 15), which is a direct consequence of both the engine axis orientation (tilt angle) and losing the circulation effect on the trailing edge. More important, the resulting upper wing flow is perfectly clean with a nice supersonic area, whereas the lower wing does not present any flow separation for a wide range of lift coefficient around $\mathrm{Cl}=0.5$. On the left of Figure 16, the upper nozzle has a constant area: while preventing any flow separation, it does not convert pressure into velocity, thus generating a poor propulsive efficiency (less thrust). This is why on the right picture the nozzle has a slight divergent profile, more suited to generate thrust.

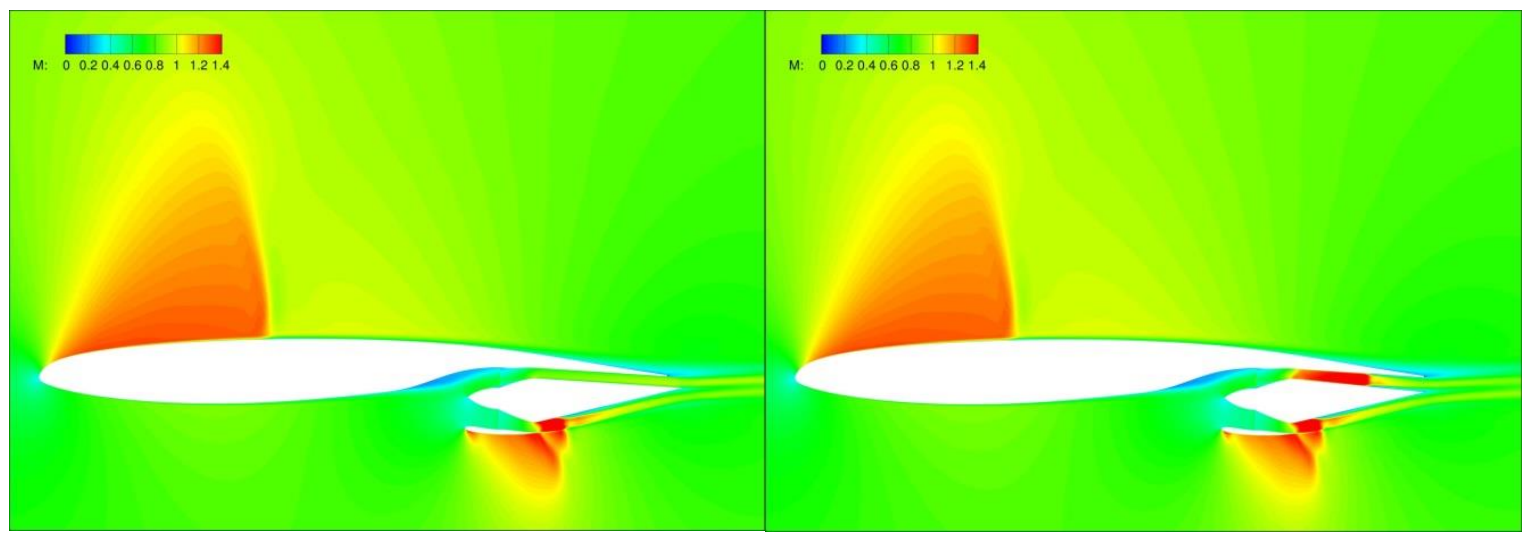

Figure 16: Current aerodynamic status - constant nozzle section (left), and slightly divergent nozzle (right). Both computations are at $\mathrm{M}=0.80,35000 \mathrm{ft}, \mathrm{AoA}=3^{\circ}$

\section{B. Wing structural sizing}

The mass and center of gravity position are two of the fundamental parameters governing aircraft performances. In most of the conceptual level tools, these parameters are determined using statistical formulations depending only on a reduced number of significant variables (wing span, fuselage diameter,...). For DRAGON, as no data are available, the aircraft mass estimation (and associated data such as CoG position, tensor of inertia components,...) is made through a full sizing of the primary structure and the computation of the secondary structures obtained using analytical and/or statistical methods. The primary structure mainly supports the loads acting on the aircraft, while the secondary structures are attached to the primary structure, but do not contribute directly to its mechanical resistance. The primary structure mainly concerns the fuselage, the wing, the tail surfaces and the landing gear while the secondary structure gathers the various flaps, ailerons and equipment (cabin, instruments, etc...). In this study, the 
fuselage is sized with analytical methods (based on strength of materials) and the wing is sized using finite elements methods in order to estimate their masses.

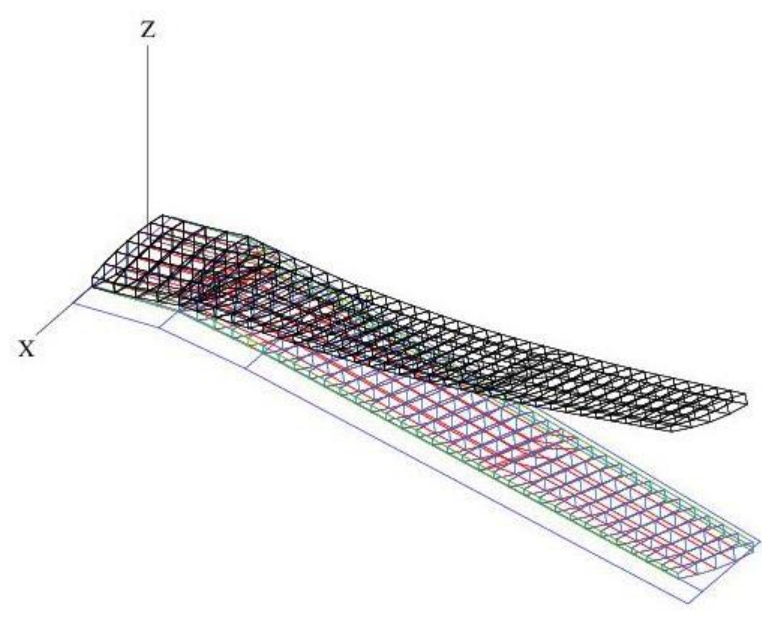

Figure 17: FE mesh of the DRAGON wing box (with 2.5 g deformation)

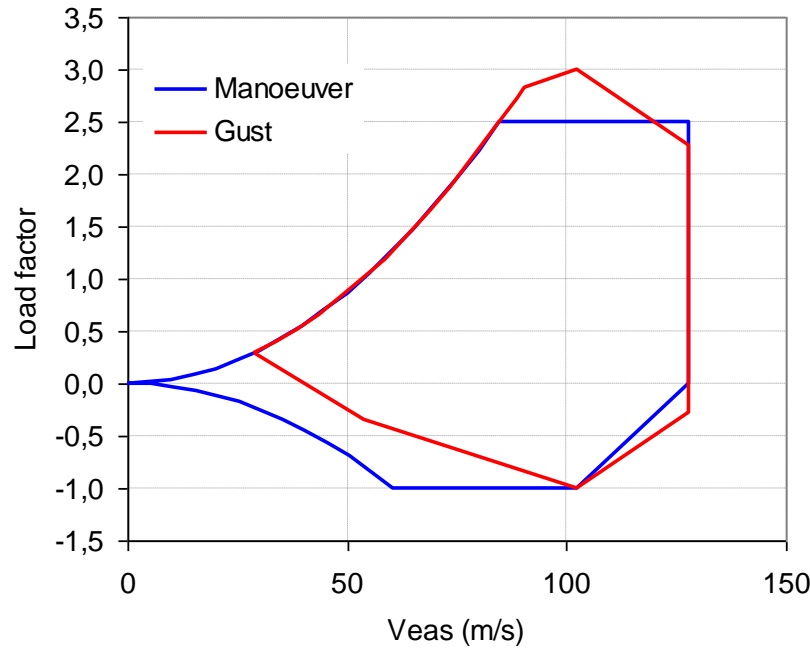

Figure 18: Generic V-n diagram used for wing sizing

Concerning the wing, a Finite Elements (FE) code is used, with plate elements to represent the wing box mechanical behavior more accurately. The wing boxes are delimited by the wing lower and upper surface skins, the leading and trailing edge spars on which the slats, flaps and ailerons are attached (their surface masses are estimated according to statistical formulations). The DRAGON wing FE mesh is composed of a few hundreds of elements to avoid high computation time (see Figure 17). V-n diagrams (manoeuver and gusts) shown in Figure 11 are computed so that the major wing loading cases can be identified. The wing is divided into boxes, separated by ribs. For each box, a specific sizing procedure determines the wing skin thickness and stringer height to satisfy skin buckling and elastic limit criterion. To size the DRAGON wing, preliminary calculations provided the weight of cables, inverters and electric motors to be integrated within the wing so that the FE model would take into account the spanwise distribution. Following a team decision to select metallic materials for the wing to be used in DRAGON, the first results (see Figure 17 for the computed $2.5 \mathrm{~g}$ wing deformation) indicated that as expected, the distributed load on the wing would reduce the bending moment. However, to meet all structural constraints with respect to torsion aspects, it has been necessary to add structural components. Thus, after comparing the FE analysis results with the original values of wing weight provided by MYSTIC (semi-empirical model), an increase of 5\% has been implemented within the sizing code.

\section{Handling qualities}

For DEP concepts, aero-propulsive synergy effects modify the resulting forces and momentum balance on the aircraft. Additional aero-propulsive coefficients have to be isolated by CFD and/or by wind tunnel tests. Moreover, thanks to distributed propulsion, differential thrust can be used for yaw and/or roll control. The size of the corresponding classical control surfaces (rudder and ailerons) could eventually been reduced. For performance (trim) and Handling Qualities (HQ) analysis, the classical flight mechanics equations have therefore to be extended with these additional coefficients in order to be able to take the new effects into account. Special care has to be spent for the (re)scaling of aero-propulsive effects as well as control surface sizes. Concerning the computation of trim conditions, new algorithms (namely optimization based ones) have to be used in order to handle the additional degrees of freedom due to the additional $n_{\text {eng }}$ engine control inputs. In order to ease the trimming and linearization, polynomial or rational approximations will be used for all coefficients rather than tabulated values. All these manipulations are carried out within an adapted Handling Qualities module that is used within the ONERA sizing code MYSTIC.

The components of this HQ module are: the flight mechanics equations, the modules for mass and inertia, aerodynamics, propulsion and aero-propulsive synergy effects. In order to be exploited efficiently, the equations and 
the modules have to be coded in a numerical environment. For time simulations and frequency analysis, modal and robustness analysis and control law design, the choice for the numerical environment has naturally gone first to the Matlab/Simulink@ environment. It aims to evaluate standard Handling Qualities HQ criteria for a given aircraft configuration. It is also designed to fit into a Multi-Disciplinary Optimization MDO process by delivering to the MDO tool margins representing how well the HQ criteria are met. It is also able to size empennages itself in a local design/optimization loop.

Details about the HQ Module

A modular solution based on Matlab objects has been coded recently. In this approach, a Model object is created. This object has a list of Force objects. One Force object corresponds to the representation of one physical phenomenon. A new Force can be added to the model (in order to take into account a certain aero-propulsive synergy effect or the landing gear force for instance) or removed easily. The Force class defines a compute method which executes the force modeling and a get method which enables to express a force in a given frame and moments at a given point. Based on that, model.newton $(x)$ will compute vehicle dynamics using $x$ as state vector. Several Criterion objects are defined in order to assess vehicle handling qualities in various flight conditions. These criteria use equilibrium solvers, linearizers and dynamic simulators. The Criterion run method will return a value representing how well the defined criterion is satisfied.

\section{Focus on the equilibrium computation or trim}

For the performance analysis of an aircraft, the designer is interested in all flight conditions where the pilot manages to stabilize the aircraft in a steady state, i.e. the aircraft does not rotate around one or several axis and it does not accelerate along one or several axis. For example, the main flight conditions of interest are straight level flight in cruise, a constant climb or descent, takeoff or landing with cross-wind (straight flight with sideslip), a constant turn with or without sideslip angle. These steady states are also called equilibrium states or trim conditions. The flight domain of an aircraft is determined by the attainable flight conditions (mass, CG, speed, altitude) where at least one of the control surfaces and/or engines is at its limits. The linearization is also realized around an equilibrium state $\dot{x}=0$ or a pseudo-equilibrium $\dot{h}=V_{z}=$ const.

A first step consists therefore in the computation of equilibrium states by fixing a certain number of magnitudes. Typical fixed magnitudes are:

- $h$

- $\quad V$ or the elevator deflection $\delta m_{i}$ of each elevator

- $\quad V z$ or the thrust setting $\delta x_{i}$ of each engine

- two magnitudes amongst $\phi, \beta, r$ and the rudder deflection $\delta n_{i}$ of each rudder

Starting with $\dot{x}=f(x, u)$, the equilibrium computation consists in finding $x_{e q}$ and $u_{e q}$ satisfying the above constraints such that $f\left(x_{e q}, u_{e q}\right)=0$ except of the equation for $h$ where $\dot{h}=V_{z}$. In the general case, this problem is an optimization problem under constraints.

The solution of an optimization problem under constraints has recently been coded in order to be able to treat all imaginable trim conditions in a generic and modular way. This solver is used by providing a set of free parameters (the ones the solver will change), a set of constrained parameters, the constraints targets (for instance all derivatives equals to 0 ) and an objective function.

For example for the hybrid electric configuration using distributed propulsion, the following constrained optimization problem can be solved:

$$
\left\{\begin{array}{l}
\min _{(x, u)} \sum_{\text {engines }} N\left(\delta x_{i}-\overline{\delta x}\right) \\
u c \dot{x}=f\left(x_{e q}, u_{e q}\right)=0
\end{array}\right.
$$

which will find an equilibrium point that minimizes thrust variation from average thrust for a given norm $N$ at a given flight point (meaning that some elements of $x_{e q}$ and $u_{e q}$ are given).

All these tools have been tested on the AMPERE concept for which WT data are available and enable us to assess its flight envelope (Figure 19 and Figure 20) ${ }^{15,20}$. 


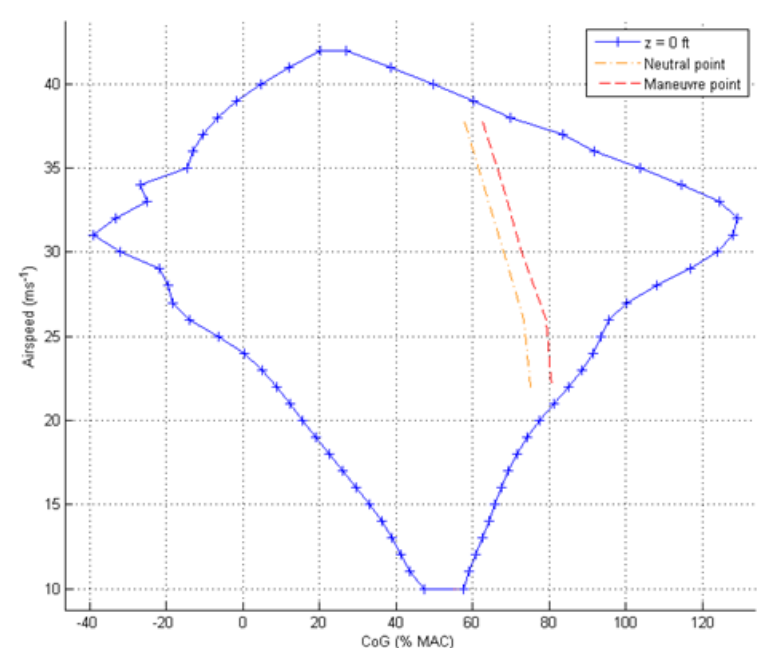

Figure 19 : AMPERE's airspeed envelope depending on its Center of Gravity (CoG) with slipstream effects

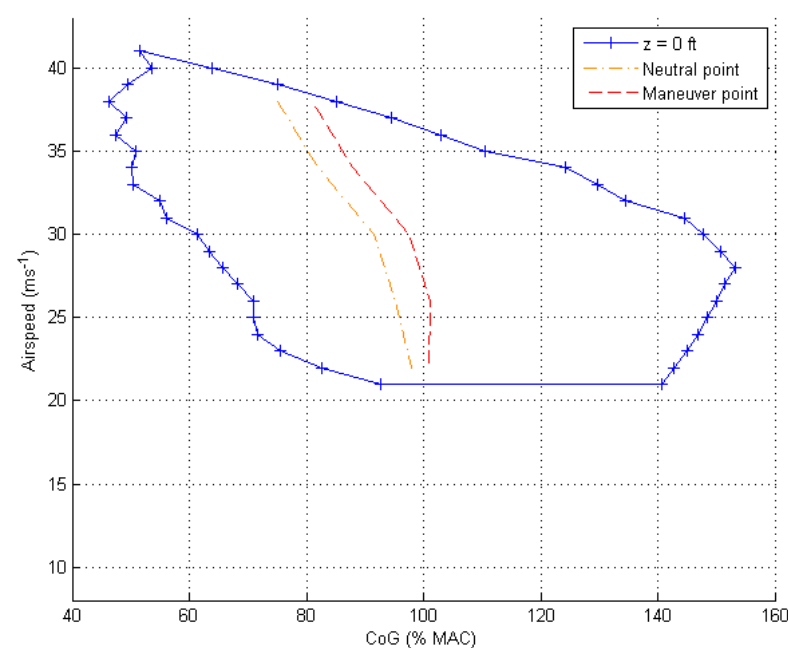

Figure 20 : AMPERE's airspeed envelope depending on its CoG without slipstream effects

A DRAGON 3D model was used to create an AVL ${ }^{22}$ mesh (Figure 21). AVL enables to easily estimate airplane stability derivatives which are critical for handling qualities assessments. The DRAGON airplane was then modelled in the above mentioned handling qualities assessment tool.

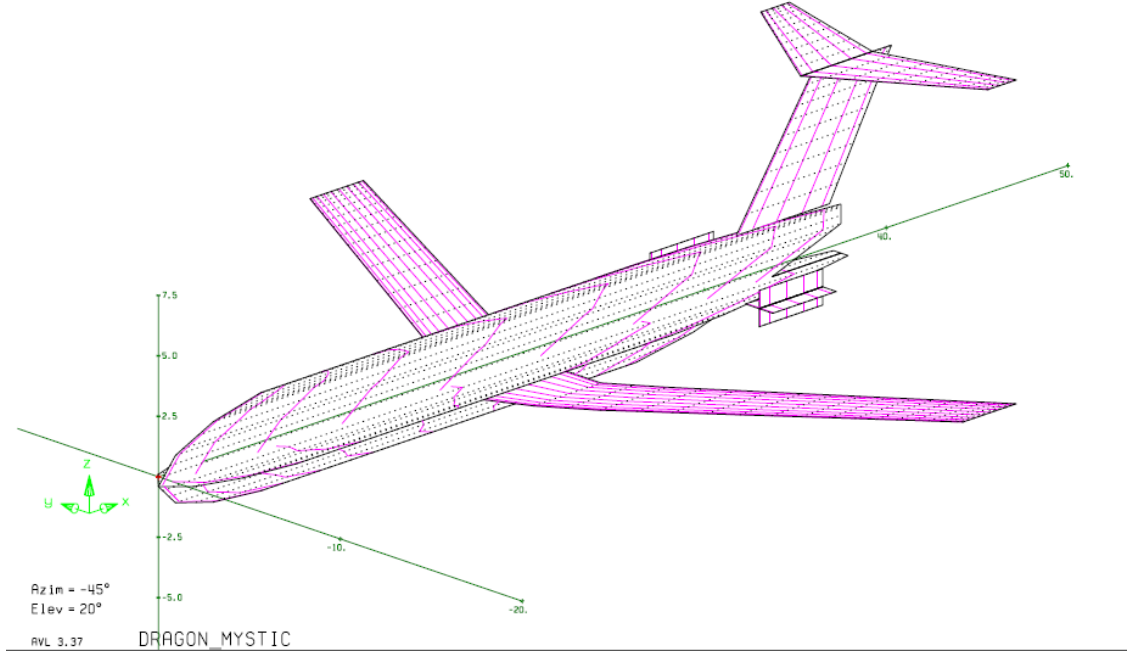

Figure 21: DRAGON AVL mesh

A classical horizontal empennage sizing process was used. This process aims to evaluate a set of longitudinal handling qualities criteria coming from certification requirements and consisting in several equilibrium computations ("trim") in various flight conditions and a stability evaluation ("manoeuver point"). Such process requires information on weights and assumptions on the Center of Gravity range.

In this early study, the following criteria have been tested (limited number):

- Trim glide: most forward CoG position on which the airplane can be balanced with horizontal stabilizer only (keeping elevator for maneuvering) while being on ILS glide slope. This criterion, as all "trim" criteria is computed at the most unfavorable airspeed. As the HTP capability to balance the airplane increases with the airspeed, this one is set to the lowest legally reachable speed.

- Trim turn: similar as previous one adding a $30^{\circ}$ bank angle and allowing some elevator deflection.

- Trim take off rotation: most forward $\mathrm{CoG}$ position where the airplane can produce sufficient pitch acceleration to perform rotation during takeoff. 
- Manoeuver point: airplane neutral dynamic stability location. This point linked to the neutral point changes with the flight conditions. Hence, an exploration of the flight domain is performed to find the most critical point (Figure 22).

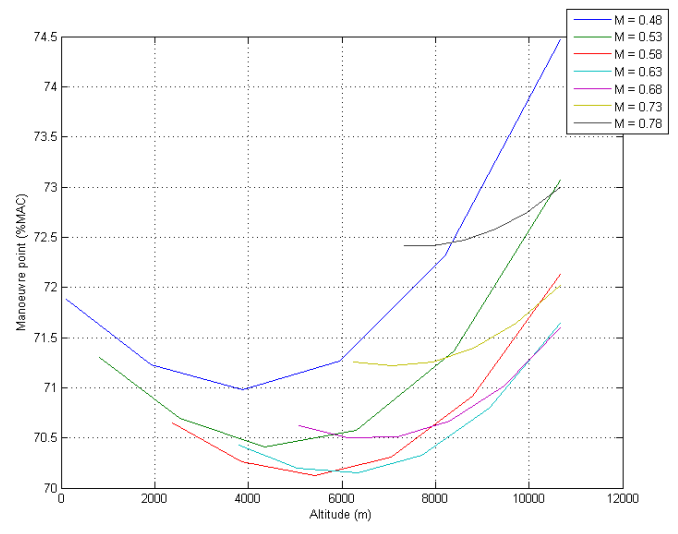

Figure 22: Manoeuver point evolution with flight point

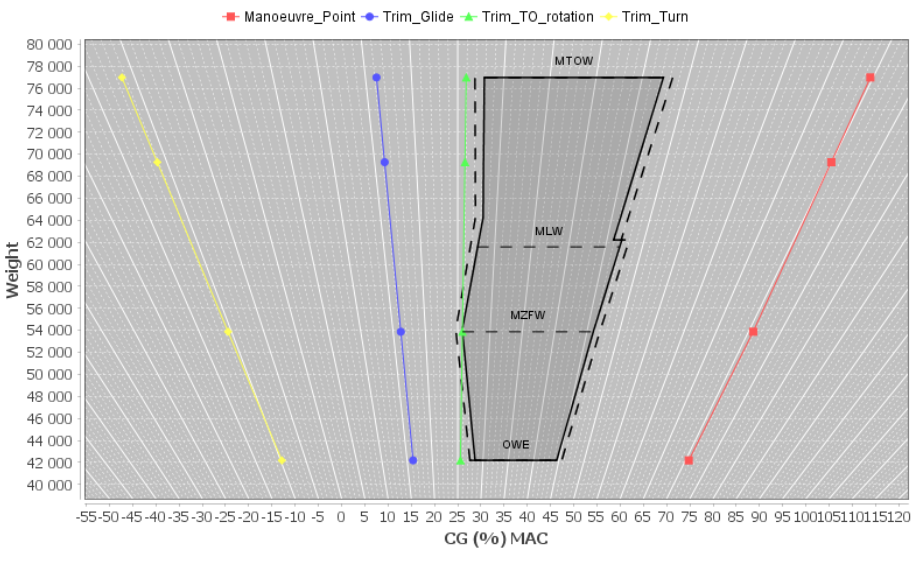

Figure 23: DRAGON W\&CG envelope with HQ criteria limitations

The optimized airplane horizontal tail plane area was computed being equal to $30.5 \mathrm{~m}^{2}$ while the original one was $31.6 \mathrm{~m}^{2}$. The resized tail results in a volume coefficient (defined by $\mathrm{V}_{\mathrm{HTP}}=\frac{\mathrm{S}_{\mathrm{HTP}} * \mathrm{~L}_{\mathrm{HTP}}}{\mathrm{S}_{\mathrm{ref}} * \mathrm{MAC}}$ ) equals to 1.0 . This value is comparable to the one of actual airplanes. In Figure 23, trim limitations must be forward the CoG position range while the manoeuver point one must be aft this range. The limiting criterion is the rotation at takeoff. An optimized airplane would have been both limited by forward and aft criteria; this configuration has some margins for either optimization or, stability and maneuverability degradation due to modeling improvements.

\section{Aeroelastic analyses}

At this early stage of the concept design and in order to evaluate the benefits and/or the drawbacks of the hybrid/distributed electric propulsion concept from an aeroelastic point of view, the following methodology has been set up:

1. Develop a simplified FE model of an aircraft based on the research concept DRAGON;

2. Update the model through modal analysis performed with a commercial FE tool (MSC Nastran);

3. Input the modal results to an in-house aeroelastic chain in order to get the aircraft mode frequencies and dampings for different flight configurations.

\section{Simplified aircraft model}

In a first step, a generic aircraft model based on the geometry of a conventional aircraft of the single aisle segment (A320 - B737 type) has been realized. It mainly consists of 2 wings and a fuselage:

- The fuselage is taken into account as a concentrated mass element (mass and mass moments of inertia) linked to the junction of both wings with Rigid Body Element (RBE) connections.

- Each wing consists of a central spar with an engine. The central spar is modelled based on a fish bone approach: the overall mass of the wing is discretized into lumped masses distributed along the wing at several stations and connected rigidly to the spar (see Figure 24).

In order to define the values of the lumped masses, the overall mass of the wing was assumed to be proportional to the volume of the spar, this latter being considered in a $1^{\text {st }}$ approximation as a truncated swept pyramidal solid with a rectangular root section whose width is proportional to the wing chord and whose thickness is varying linearly with the wingspan (see Figure 25, left). On the other hand, the different spar stations are linked together with flexible joints representing localized elasticity of the wing. The bending and torsion laws of wing stiffness distributions were taken similar to those of a common aircraft (see Figure 25). 


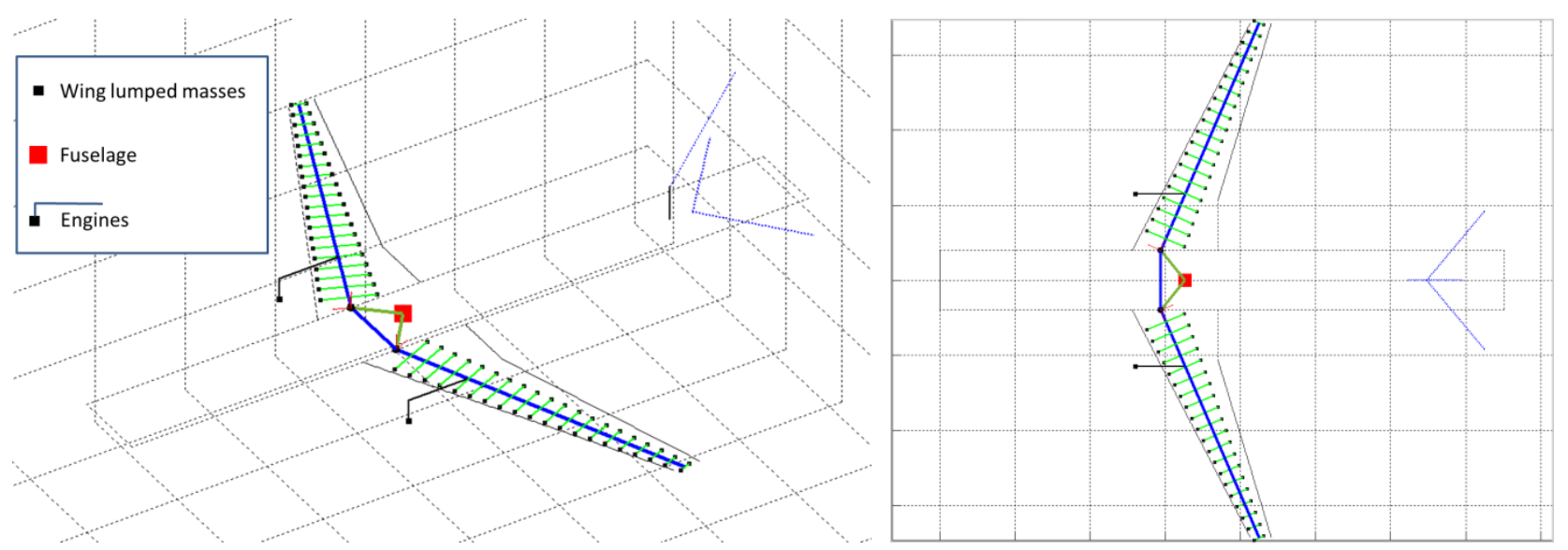

Figure 24: Generic Aircraft Model (iso view on the left, top view on the right)
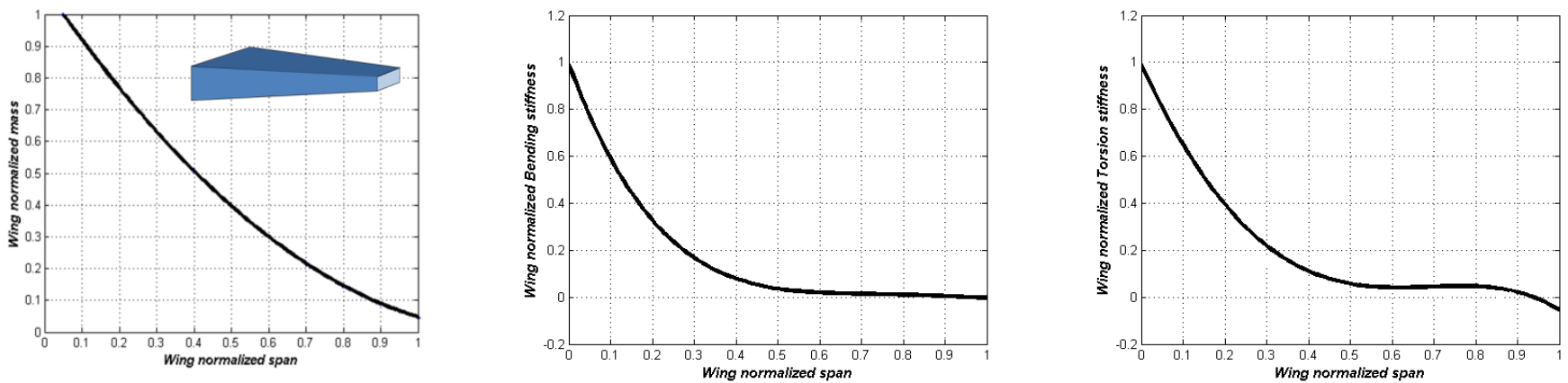

Figure 25: Distribution of wing normalized mass (left), bending stiffness (center) and torsion stiffness (right)

In a $2^{\text {nd }}$ step, a DRAGON model was built following the same approach, (see Figure 26):

- alike distributions laws updated with the overall wing masses coming from the structural sizing studies;

- a fuselage modelled as a heavy concentrated body including, inter alia, the turboshafts, the central tank and the T tail;

- additional distributed masses representative of the electric motors and the corresponding ducted fans, inverters/converters and electric cabling.

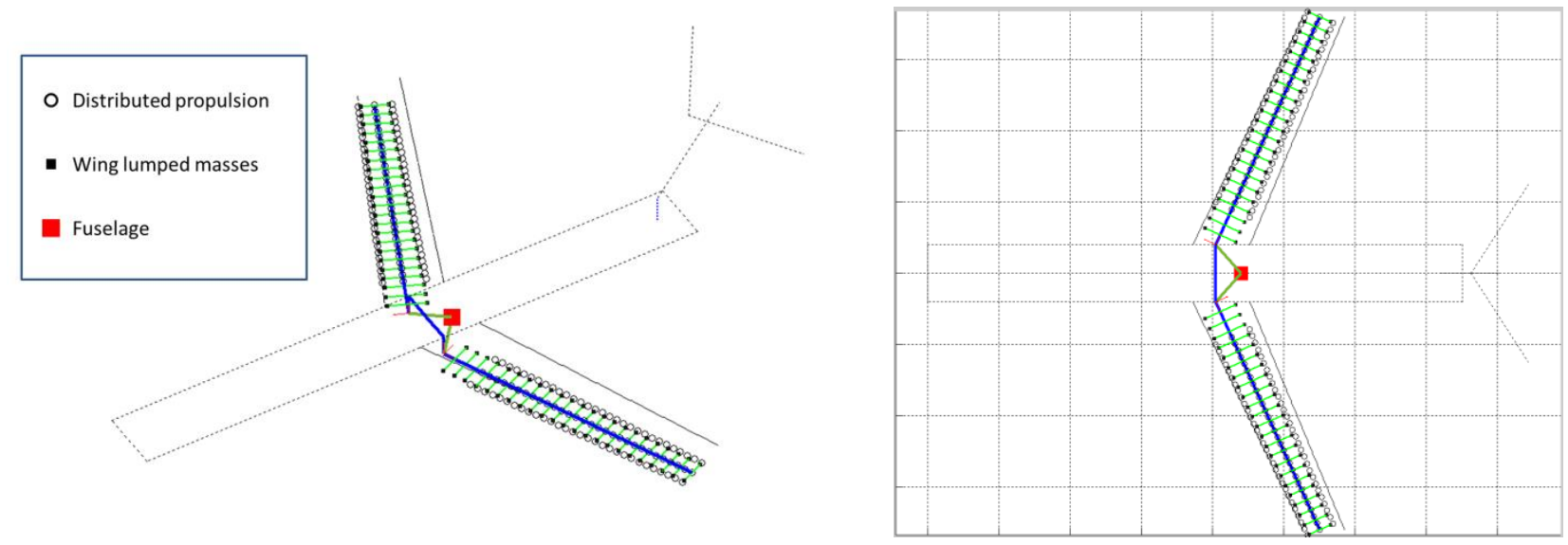

Figure 26 : DRAGON model (iso view on the left, top view on the right)

Modal analysis 
The modal analysis of the models has been performed with Nastran $\bigodot$. The stiffnesses distributions of the generic aircraft model were adjusted so that the $1^{\text {st }}$ modal frequencies of the aircraft dynamic model could match those of a conventional aircraft. The DRAGON stiffnesses of the wing were taken at this preconcept stage identical to those of the generic model. Figure 27 to Figure 29 show the derived first 6 normal modes.
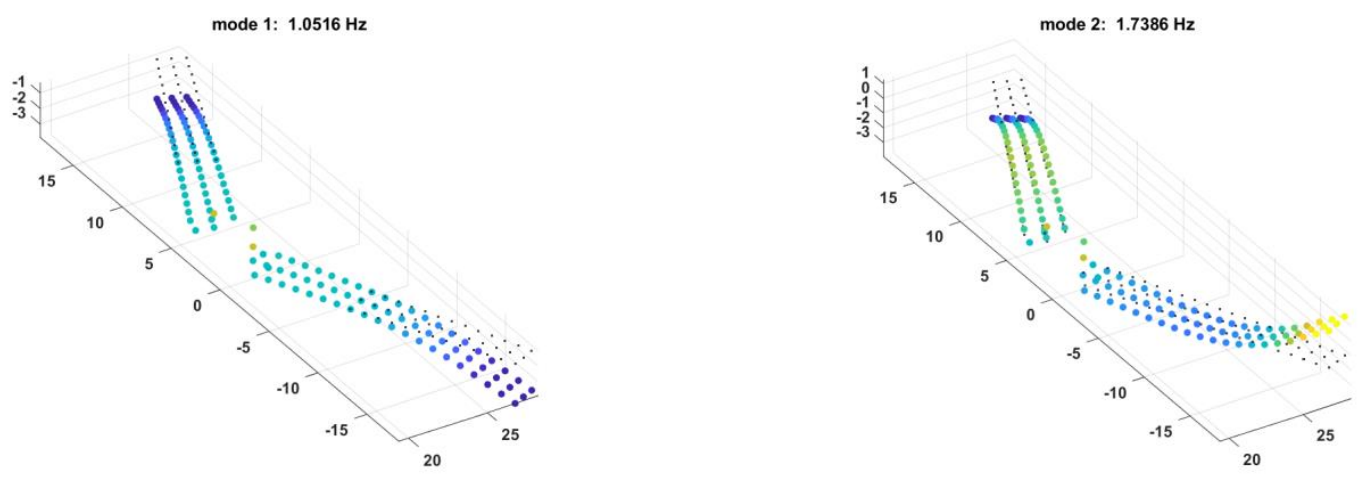

Figure 27: DRAGON model normal modes $-1^{\text {st }}$ symmetric (left) and antisymmetric bending (right)
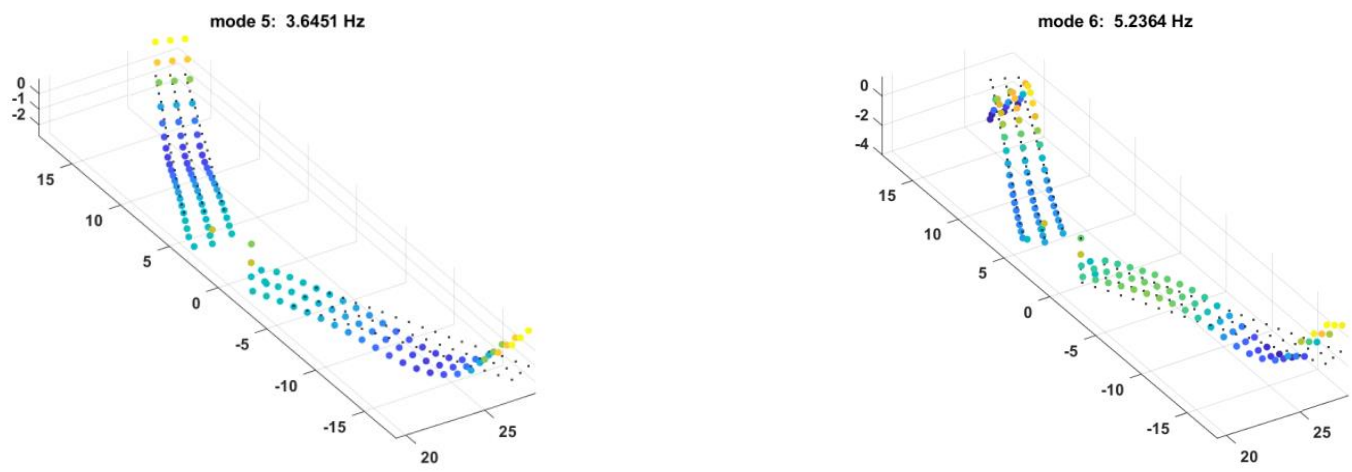

Figure 28: DRAGON model normal modes $-2^{\text {nd }}$ symmetric (left) and antisymmetric (right) bending.
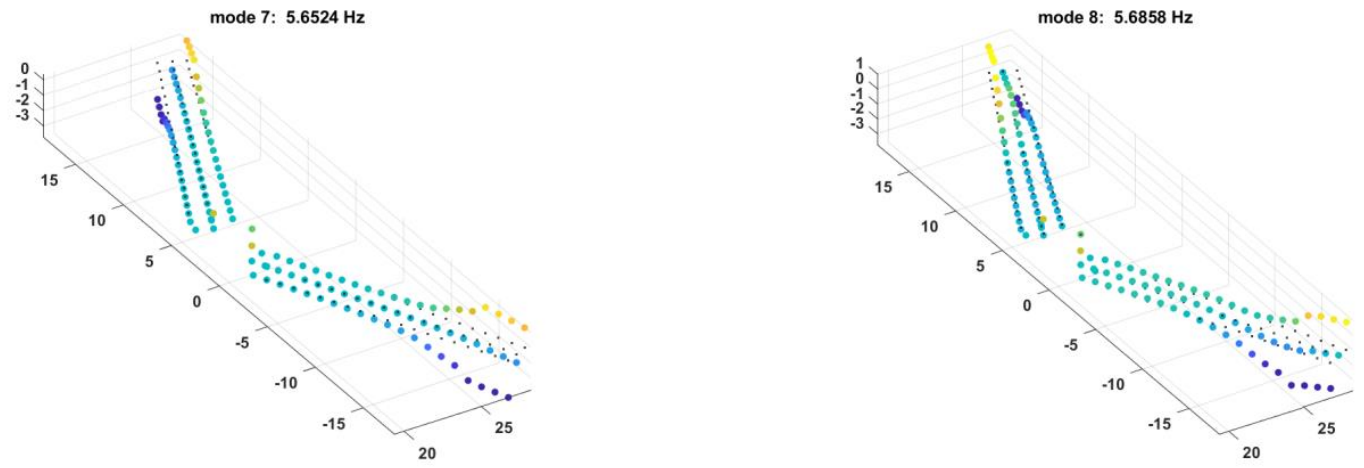

Figure 29: DRAGON model normal modes - $1^{\text {st }}$ symmetric (left) and antisymmetric torsion (right).

$\underline{\text { Flutter analysis }}$

The overall process can be mapped as followed: 
- Computation of the structural normal modes of the aircraft; these latter are obtained using Nastran (C) solution SOL 103.

- Creation of an aerodynamic meshing based on the geometry of the wings.

- Projection of the structural normal modes on the aerodynamic meshing through an interpolation process; these fitted modes are then called "aero" modes.

- Computation of the unsteady aerodynamic loads on the aerodynamic mesh (for harmonic oscillations using a panel method namely the Doublet Lattice method; the main inputs in this step are the flight conditions (altitude, Mach number) and the frequencies of excitation.

- Computation of the generalized aerodynamic forces (GAF) for the different frequencies of vibration by :

- projecting the loads on the "aero" modal basis

- computing the influence of vibration of each mode on the other modes resulting in a GAF matrix including direct and crossed terms

$$
\frac{1}{2} \rho V^{2} \times G A F=\int P n \cdot \varphi d \sigma
$$

where $\mathrm{P}$ is the pressure, $\varphi$ a mode, $\mathrm{n}$ the normal to the surface, $\rho$ the air density and $\mathrm{V}$ the velocity

- Flutter analysis using the in-house software named CAPRI (Chaine Aéroélastique de Prévision de la Réponse et des Instabilités) ${ }^{23}$ which solves the coupled "fluid-structure" equations:

$$
\mu_{G} \ddot{q}+\beta_{G} \dot{q}+\gamma_{G} q+\frac{1}{2} \rho V^{2} \times G A F=0
$$

where $\mu_{G}, \beta_{G}, \gamma_{G}$ are the generalized mass, damping and stiffness matrices.

It should be noted that no structural damping was considered in the computations.

Two DRAGON configurations have been considered relating to different propulsive elements distribution in the wings: configuration $\mathrm{n}^{\circ} 1$ is mainly composed of 60 electric motors whereas configuration $\mathrm{n}^{\circ} 2$ is composed of 40 motors. The overall masses of the corresponding propulsive elements are however pretty close (variation of less than $5 \%$ ), resulting in close normal modes and hence a similar aeroelastic behavior. Figure 30 shows variations of the modal frequencies and dampings for configuration $\mathrm{n}^{\circ} 1$ with flight speed at a cruise altitude of $10000 \mathrm{~m}$ (right hand side) and with altitude at a Mach speed number of 0.7 (left hand side). The analyses do not exhibit a specific risk except for the low altitude and high speed case due to the coupling between 2 bending modes. It is shown however that this kind of instability could be cancelled by increasing the bending stiffness of the wing (see Figure 31 ).
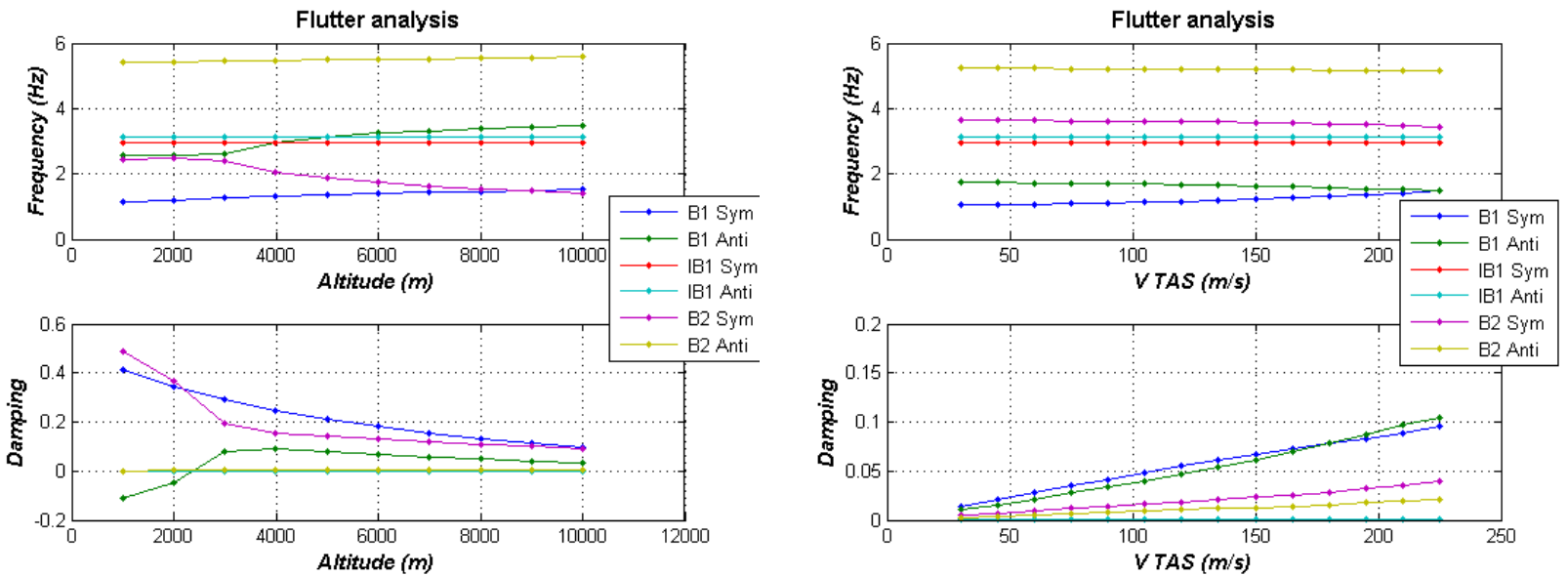

Figure 30: Flutter analysis of configuration $n^{\circ} 1$ (left: altitude variation at $M=0.7$; right: speed variation at altitude $=10000 \mathrm{~m}$ ) 

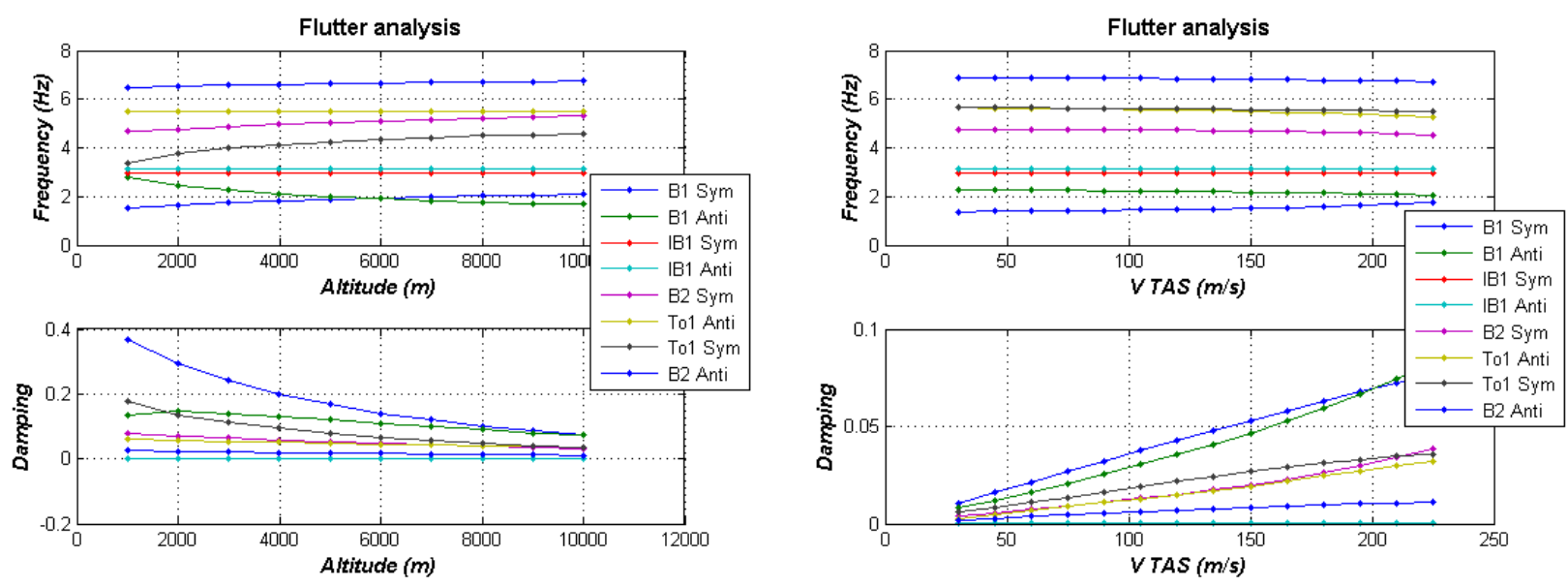

Figure 31: Flutter analysis of configuration $\mathrm{n}^{\circ} 1$ with increased bending stiffness (left: altitude variation at $M=0.7$; right: speed variation at altitude $=10000 \mathrm{~m}$ )

\section{E. First estimations of overall aircraft performance}

For the first overall performance assessment of DRAGON, ONERA uses its Python based tool called MYSTIC ${ }^{10}$. The sizing process for Hybrid Electric Distributed Propulsion aircraft is the same as the one presented by ISAESUPAERO $^{9}$ except that batteries are no more taken into account because of the selected electrical architecture. The reference mission used in the sizing loop is characterized by a number of passengers ( 150 in two classes), a cruise Mach number of 0.78 and a design range of $1200 \mathrm{NM}$. This latest value has been selected in order to provide certain flexibility to airlines considering the classical operational range of $800 \mathrm{NM}$ used for Small Medium Range aircraft.

In order to assess the benefits of DRAGON, an advanced "tube and wing" configuration using 2 turbofans with an estimated Entry Into Service in 2035 is used as reference. To better estimate the performances of such future airplane, key assumptions taken into account during the sizing are made: the maximum lift-to-drag ratio in cruise is about 19, the reduction in Thrust Specific Fuel Consumption is about 20\% with respect to the available IAE V2500 database $^{24}$ and material improvements reduce the weight of the airframe (wing, fuselage, landing gear, cabin seat) ${ }^{9}$. The sizing loop achieved through MYSTIC leads to an civil transport aircraft that requires a mission fuel weight of about 7 tons to transport 150 passengers over $1200 \mathrm{NM}$ at a cruise Mach number of 0.78 (MTOW $=58.85$ tons including 7.7 tons of propulsion system).

When sizing the DRAGON concept with MYSTIC, all components of the Hybrid Electric Distributed Propulsion chain (see Figure 4) have been considered including cooling. However, there are still many uncertainties regarding the installed performances of the different components. Thus, 3 possible evolutions have been identified for an EIS in 2035: negligible, moderate and significant. Based on different sources ${ }^{25,26,27}$, ONERA internal studies and iterations during workshops organized within the Clean Sky 2 programme, Table 1 details the values that have been considered for the 3 different scenarios. To complete the information about the propulsion chain, it must be noted that for electricity generation, turboshaft performances (maximum power and Power Specific Fuel Consumption as functions of Mach number and altitude) have been generated through $\mathrm{GSP}^{28}$. In addition, the cable sizing relies on the assumption of a current of $360 \mathrm{~A}$ for the 3 cases.

In this conceptual exploration, the crucial failure case implemented in MYSTIC for the HEDP chain corresponds to the One Turboshaft Inoperative condition. This means that the functioning turboshaft shall provide sufficient power to maintain a slope of $2.4 \%$ in a takeoff condition. Considering the pessimistic scenario of negligible evolutions at component performance level, sizing iterations lead to the installation of 2 turboshafts producing a maximum power of $15 \mathrm{MW}$ each. At the other hand of the propulsion chain, it is assumed to have 40 electric motors. For the sizing of these motors, the case of one PMU failure is considered: in this condition, all available power must be absorbed by 30 electric motors.

Table 1: Technology scenarios for components of the DRAGON Hybrid Electric Distributed Propulsion chain Evolution towards 2035 


\begin{tabular}{|l|l|c|c|c|}
\multicolumn{2}{|c|}{} & Negligible & Moderate & Significant \\
\hline Turboshaft & Power density $[\mathrm{kW} / \mathrm{kg}]$ & 7 & 8 & 9.5 \\
\hline \multirow{3}{*}{ Generator } & Power density $[\mathrm{kW} / \mathrm{kg}]$ & 13.5 & 15 & 19 \\
\cline { 2 - 5 } & Efficiency & 0.9 & 0.95 & 0.98 \\
\hline \multirow{3}{*}{ Inverter /Converter } & Power density $[\mathrm{kW} / \mathrm{kg}]$ & 15 & 20 & 25 \\
\cline { 2 - 5 } & Efficiency & 0.98 & 0.99 & 0.995 \\
\cline { 2 - 5 } & Power density $[\mathrm{kW} / \mathrm{kg}]$ & 13.2 & 19 & 25 \\
\cline { 2 - 5 } & Efficiency & 0.96 & 0.98 & 0.99 \\
\hline \multirow{2}{*}{ Electric motor } & Power density $[\mathrm{kW} / \mathrm{kg}]$ & 13.2 & 19 & 25 \\
\cline { 2 - 5 } & Efficiency & 0.96 & 0.98 & 0.99 \\
\hline Cables & Maximum voltage $[\mathrm{kV}]$ & 2.16 & 3 & 5 \\
\cline { 2 - 5 } & Linear density $[\mathrm{kg} / \mathrm{m}]$ & 1 & 0.8 & 0.5 \\
\hline Cooling system & Power density $[\mathrm{kW} / \mathrm{kg}]$ & 2 & 2.5 & 3 \\
\hline
\end{tabular}

Finally, ducted fans characterized by a Fan Pressure Ratio of 1.4 (today's recent engines have a Fan Pressure Ratio of 1.5) are connected to the electric motors. Regarding aerodynamics, given the fact that the large number of fans increases the wetted area, the DRAGON concept efficiency in cruise is about 17. About structure and weight aspects, this initial sizing loop considers the 5\% increase of wing mass (metallic material) to take into account the outcomes of the wing structural analysis. When assessing the global performances through the Multidisciplinary Design Analysis, the key aircraft parameters with respect to technology evolutions are plotted in Figure 32 against the reference aircraft.

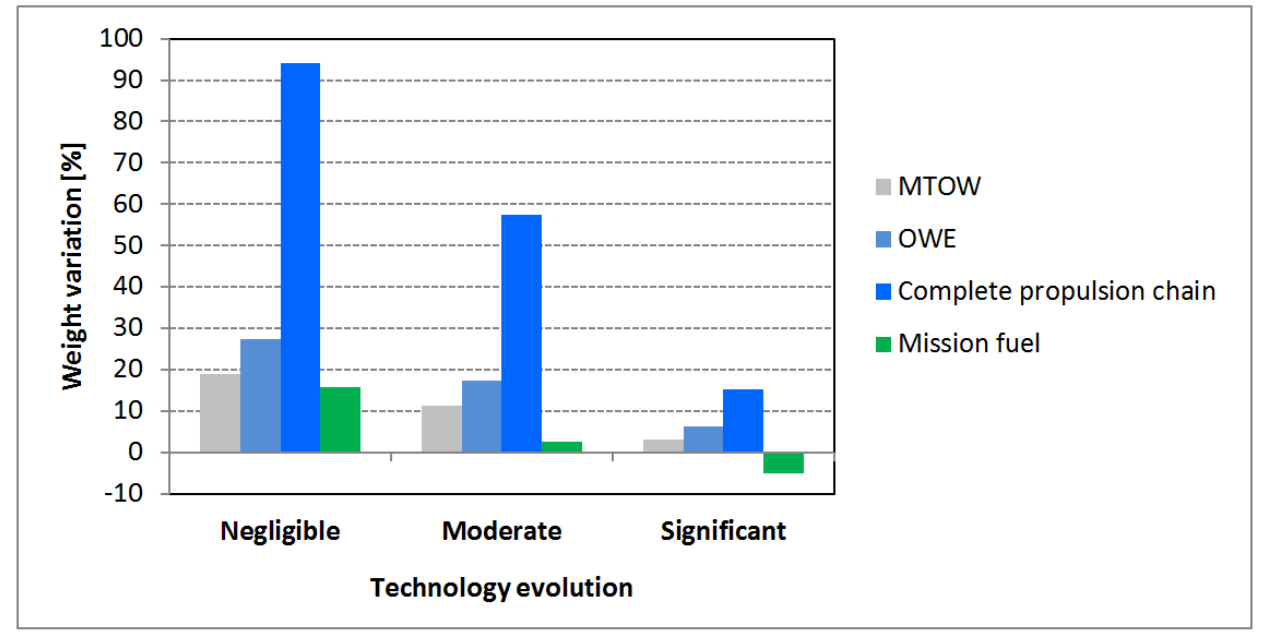

\section{Figure 32: DRAGON characteristics for different technology evolution scenarios with respect to the reference aircraft (EIS 2035)}

The rationale for using hybrid electric technology to reduce the Fan Pressure Ratio for fuel burn reduction is clear. However, the preliminary results show that the weight penalty associated to the complete propulsion chain leads to an increase of fuel burn with respect to the reference aircraft for the negligible and moderate technology evolution scenarios. When significant improvements at technology level are considered, the weight of the complete propulsion chain becomes less critical and distributed propulsion offers a 5\% reduction in mission fuel. To finalize the assessment of DRAGON's performances with respect to technology evolutions, it is important to verify the impact of the turboshaft efficiency. In this regards, considering the Moderate technology scenario of Table 1, reductions of 5\% and 10\% in Power Specific Fuel consumption converges respectively to a fuel burn reduction of $3 \%$ and $8 \%$ with respect to the reference aircraft.

To conclude these initial mission assessments of DRAGON, it has been decided to change the required design of the aircraft to match the classical operational range of $800 \mathrm{NM}$ for Small Medium Range aircraft. Considering this change at Top Level Aircraft Requirements, the conventional configuration based on 2035 technologies requires $5600 \mathrm{~kg}$ of fuel to complete the mission. For this same distance and a Moderate technology evolution scenario, 
DRAGON requires only about $5120 \mathrm{~kg}$ which corresponds to a reduction of $8.5 \%$ in fuel burn. Then, still considering the moderate technology evolution scenario for the electrical components performances, it seems that DRAGON would be more efficient than the 2035 "tube and wing" configuration as long as the design range remains below 1100 NM.

\section{Conclusion and perspectives}

Hybrid Electric Distributed Propulsion is considered as a key technology that could lead to better propulsive efficiency of large passenger airplanes ${ }^{26}$. As today's airplanes used around the world by airlines fly at a cruise Mach number of about 0.8, ONERA decided to assess the benefits and issues associated with the integration of high speed distributed propulsion on a 150 passenger aircraft with a 1200 NM range. Such concept presents many innovative elements with respect to a classical "tube and wing" configuration. Thus, it has been decided to carry out concurrent disciplinary studies as well as overall aircraft assessments very early in the conceptual design phase to acquire more knowledge about this potential disruptive aircraft. To enable parallel studies among the specialists, a research baseline concept called DRAGON (Distributed fans Research Aircraft with electric Generators by ONERA) has been defined. The selected configuration has been solely designed in order to investigate as good as possible the high speed distributed propulsion technology: indeed, operational constraints to be taken into account in the design and optimization of a viable airliner have not been considered. Subsequently, various investigations on DRAGON aspects took place:

- At aerodynamics level, the 2D studies allowed a better understanding of the interactions between the airfoil and the fan located in the rear part of the lower surface. After various iterations, a good design has been achieved for which the flow on the upper side has a clean supersonic area while the lower side does not feature any flow separation. In this domain, the next steps are to reduce the nozzle cone length, then to move from a 2D study to a 3D analysis, and finally to design the "propulsive flap" once the cruise design is correct. Those expected results will be presented in future papers.

- For aircraft performance assessment, one key aspect is the accurate mass estimation of airframe components. For high speed distributed propulsion, as no analytical models could be used, a FE model of the DRAGON wing has been defined and used to estimate the weight. This study highlighted the benefits of distributing masses along the span with respect to bending moment. However, it also pointed out a global increase of wing weight with respect to a classical structure because of the torsion that is generated along the chord by the distributed components of the propulsion chain. Future work consists in assessing the effects on wing weight of a continuous fan fairing that would have a structural role.

- Concerning the aeroelastic behavior of such a concept, a simplified lumped parameter model has been developed in order to identify as rapidly as possible potential stoppers. In the presented work, 2 configurations of the DRAGON concept based on this parametric FE model and conceptual level structural data have been analyzed. Overall, both distributed propulsion configurations exhibit an almost alike behavior. Besides, no critical aeroelastic issue was identified in cruise flight except for a flutter configuration at low altitude and high speed, which could nevertheless be cancelled by increasing the bending stiffness of the wing. It is planned to further keep on the investigations by using a more refined model enhanced with updated data stemming from the FE model used for wing sizing studies.

- Regarding handling qualities, the preliminary studies performed so far on the DRAGON configuration did not reveal any strong limitation on longitudinal handling qualities as the configuration shows sufficient margins. However, as detailed in the aerodynamics study section, aero-propulsive effects will impact DRAGON's handling qualities. Today, there is no sufficient data to take those effects into account and using a derivation of AMPERE aero-propulsive effects would be hazardous as the engine installation is radically different. The next task will naturally focus on the revision of the dynamic behavior of DRAGON taking into account such effects and the study of lateral handling qualities.

- From a design process point of view, the first estimations of DRAGON overall performances enabled the review of the sizing loops taking into account some failure cases. As the effectiveness of the high speed distributed propulsion fully depends on the evolution of hybrid electric technology, various scenarios have been considered. When analyzing the results for all the cases, benefits at fuel consumption level appear only for significant technology developments. However, when considering the enhancement of turboshaft efficiency or a revision of the mission range, moderate technological progresses are sufficient to generate benefits for the DRAGON configuration with respect to the 2035 reference configuration. In order to provide advanced assessments, next developments will concentrate on incorporating more disciplinary and systems knowledge into MYSTIC. 
Designing a hybrid electric propulsion transport aircraft flying at a high cruise Mach number over a range that meets airlines flexibility requirements is a challenge. This challenge is even harder because the super optimized reference configuration is very efficient. However, in this conceptual exploration of DRAGON considering different technology development scenarios as well as mission design range variations, benefits in terms of fuel burn reduction have been identified. Although small, these gains are obtained for a configuration that is not at all optimized. There is therefore a large design space to be explored for improvements at disciplinary level and at systems level. Besides, distributed propulsion offers synergies at overall aircraft level that would further improve fuel consumption (aeropropulsive effects and lateral control among others).

ONERA will thus continue the maturation of the high speed Hybrid Electric Distributed Propulsion technology on the DRAGON concept through refined high fidelity disciplinary studies combined with multidisciplinary design analyses and optimizations at aircraft level.

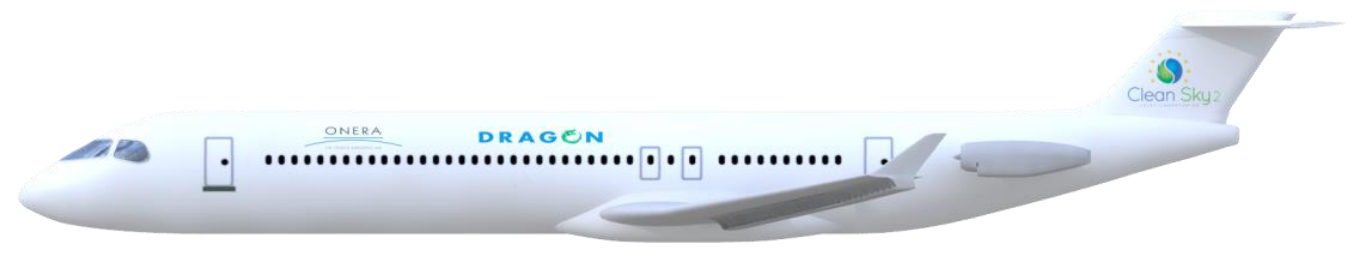

Figure 33: Side view of the DRAGON concept

\section{Acknowledgements}

The authors would like to thank:

- The European Commission for the financial support in the frame of Clean Sky 2 Large Passenger Aircraft Innovative Aircraft Demonstration Platform "LPA IADP" (contract number: CSJU-CS2-GAM-LPA-20142015-01)

- David Donjat for his guidance towards thermal aspects assessment;

- Ludovic Wiart for his inputs on aerodynamics aspects;

- Alessandro Sgueglia for his contribution in the overall aircraft design process;

- Airbus, DLR, NLR and the University of Delft for the positive exchanges during workshops in the frame of the European Programme Clean Sky 2.

\section{References}

1 J. Roskam, “Airplane Design, Part II : Preliminary Configuration Design and Integration of the Propulsion System”, DARCorporation, 2017

2 M. Brown, R. Vos, "Conceptual Design and Evaluation of Blended-Wing Body Aircraft", AIAA 2018-0522, 2018

3 E. Moerland, T. Pfeiffer, D. Böhnke, J. Jepsen, S. Freund, C. M. Liersch, G. Pinho Chiozzotto, C/ Klein, J. Scherer, Y. J. Hasan, J. Flink, "On the Design of a Strut-Braced Wing Configuration in a Collaborative Design Environment", AIAA 20174397, 2017

4 “Aircraft Electrical Propulsion - The Next Chapter of Aviation?", Roland Berger LTD, 2017

5 C. Döll, B. Paluch, A. Guigon, D. Fraboulet, "Conceptual feasibility study for a fully electrically powered regional transport aircraft", $29^{\text {th }}$ International Council of Aeronautical Sciences ICAS, 2014 [online database] URL: http://publications.onera.fr/exl-php/docs/ILS_DOC/281623/DOC414926_s1.pdf, [cited 10 December 2018]

6 K. A. Deere, S. Viken, M. B. Carter, J. K. Viken, D. E. Cox, M. R. Wiese, N. L. Farr, "Computational Component Build-up for the X-57 Maxwell Distributed Electric Propulsion Aircraft", AIAA 2018-1275, 2018

7 M. J. Armstrong, M. Blackwelder, A. Bollman, C. Ross, A. Campbell, C. Jones, P. Norman, "Architecture, Voltage, and Components for a Turboelectric Distributed Propulsion Electric Grid", NASA CR-2015-218440, 2015

8 J. Hermetz, M. Ridel, C. Doll, "Distributed electric propulsion for small business aircraft a concept-plane for key-technologies investigations", $30^{\text {th }}$ International Council of Aeronautical Sciences ICAS, 2016

9 A. Sgueglia, P. Schmollgruber, N. Bartoli, O. Atinault, E. Benard, J. Morlier, "Exploration and Sizing of a Large Passenger Aircraft with Distributed Ducted Electric Fans", AIAA 2018-1745, 2018

10 S. Defoort, M. Méheut, B. Paluch, R. Liaboeuf, R. Murray, D. Mincu, J.-M. David, "Conceptual design of disruptive aircraft configurations based on High-Fidelity OAD process", AIAA Aviation 2018, 2018

11 P. Sforza, "Commercial Airplane Design Principles", Elsevier Aerospace Engineering Series, Butterworth-Heinemann, 2014

12 "First Airbus A320neo Rolls Out" [Website] URL: https://www.airliners.net/forum/viewtopic.php?t=574041, [cited 10 December 2018]

13 M. Moore, "Distributed Electric Propulsion (DEP) Aircraft", NASA, 2012 
14 A. T. Wick, J. R. Hooker and C. J. Hardin, C. H. Zeune, "Integrated Aerodynamic Benefits of Distributed Propulsion", AIAA 2015-1500, 2015

15 R. Liaboeuf, E. Dillinger, “ONERA's small business concept plane with Distributed Electric Propulsion longitudinal handling qualities evaluation", $18^{\text {th }}$ Onera-DLR Aerospace Symposium, 2018

16 J. Roskam, "Lessons Learned in Aircraft Design, the devil is in the details", DARcorporation, 2017

17 M. Fujino, "Design and Development of the HondaJet", Journal of Aircraft, Vol. 42, No. 3, pp. 755-764, 2005

18 "Additional Center Tanks" [Website] URL: https://services.airbus.com/upgrade/operations/operations-extension/additionalcenter-tanks-act, [cited 11 December 2018]

19 P. Ciampa, B. Nagel B., "Towards the 3rd generation MDO collaborative environment", $30^{\text {th }}$ Congress of the International Council of the Aeronautical Sciences ICAS, Daejeon, Korea, 2016

20 C. Döll, C. Toussaint, R. Liaboeuf, J. Hermetz, C. Verbeke, M. Ridel, E. Dillinger, "Handling Qualities of ONERA's small business concept plane with Distributed Electric Propulsion", $31^{\text {st }}$ International Council of Aeronautical Sciences, 2018

21 A. Isikveren et al., "Distributed Propulsion and Ultra-high By-Pass Rotor Study at Aircraft Level", The Aeronautical Journal, Volume 119, No 1221, 2015

22 "AVL - Athena Vortex Lattice" [website] URL: http://web.mit.edu/drela/Public/web/avl/, [cited 10 December 2018]

23 R. Arnaud, "Étude d'un problème d'optimisation en aéroélasticité avec incertitudes”, PhD Dissertation, Mécanique des structures, Ecole Centrale Paris, 2014

24 "CeRAS, Central Reference Aircraft data System" [website] URL: http://ceras.ilr.rwthaachen.de/trac/wiki/CeRAS/AircraftDesigns/CSR01, [cited 11 December 2018]

25 R. Dyson, "NASA Hybrid Electric Aircraft Propulsion”, NIEA Biomimicry Summit, 2017

26 N. Madavan et al., "A NASA perspective on electric propulsion technologies for commercial aviation", Workshop on Technology Roadmap for Large Electric Machines, 2016

27 F. Anton "High-output motor technology for hybrid-electric aircraft", Electric \& Hybrid Aerospace Technology Symposium, 2017

28 “GSP, Gas Turbine Simulation Program”, [website] URL: https://www.gspteam.com/, [cited 10 December 2018] 